\title{
The Contemporary Theory of Metaphor
}

\section{George Lakoff}

(c) Copyright George Lakoff, 1992

To Appear in Ortony, Andrew (ed.) Metaphor and Thought (2nd edition), Cambridge University Press.

Do not go gentle into that good night. -Dylan Thomas

Death is the mother of beauty ... -Wallace Stevens, Sunday Morning

\section{Introduction}

These famous lines by Thomas and Stevens are examples of what classical theorists, at least since Aristotle, have referred to as metaphor: instances of novel poetic language in which words like mother, go, and night are not used in their normal everyday senses. In classical theories of language, metaphor was seen as a matter of language not thought. Metaphorical expressions were assumed to be mutually exclusive with the realm of ordinary everyday language: everyday language had no metaphor, and metaphor used mechanisms outside the realm of everyday conventional language. The classical theory was taken so much for granted over the centuries that many people didn't realize that it was just a theory. The theory was not merely taken to be true, but came to be taken as definitional. The word metaphor was defined as a novel or poetic linguistic expression where one or more words for a concept are used outside of its normal conventional meaning to express a similar concept. But such issues are not matters for definitions; they are empirical questions. As a cognitive scientist and a linguist, one asks: What are the generalizations governing the linguistic expressions re ferred to classically as poetic metaphors? When this question is answered rigorously, the classical theory turns out to be false. The generalizations governing poetic metaphorical expressions are not in language, but in thought: They are general map pings across conceptual domains. Moreover, these general princi ples which take the form of conceptual mappings, apply not just to novel poetic expressions, but to much of ordinary everyday language. In short, the locus of metaphor is not in language at all, but in the way we conceptualize one mental domain in terms of another. The general theory of metaphor is given by characterizing such crossdomain mappings. And in the process, everyday abstract concepts like time, states, change, causation, and pur pose also turn out to be metaphorical. The result is that metaphor (that is, cross-domain mapping) is absolutely central to ordinary natural language semantics, and that the study of literary metaphor is an extension of the study of everyday metaphor. Everyday metaphor is characterized by a huge system of thousands of cross-domain mappings, and this system is made use of in novel metaphor. Because of these empirical results, the word metaphor has come to be used differently in contemporary metaphor research. The word metaphor has come to mean a cross-domain mapping in the conceptual system. The term metaphorical expression refers to a linguistic 
expression (a word, phrase, or sentence) that is the surface realization of such a crossdomain mapping (this is what the word metaphor referred to in the old theory). I will adopt the contemporary usage throughout this chapter. Experimental results demonstrating the cognitive reali ty of the extensive system of metaphorical mappings are discussed by Gibbs (this volume). Mark Turner's 1987 book, Death is the mother of beauty, whose title comes from Stevens' great line, demonstrates in detail how that line uses the ordinary system of everyday mappings. For further examples of how literary metaphor makes use of the ordinary metaphor system, see More Than Cool Reason: A Field Guide to Poetic Metaphor, by Lakoff and Turner (1989) and Reading Minds: The Study of English in the Age of Cognitive Science, by Turner (1991). Since the everyday metaphor system is central to the understanding of poetic metaphor, we will begin with the everyday system and then turn to poetic examples.

\section{Homage To Reddy}

The contemporary theory that metaphor is primarily conceptual, conventional, and part of the ordinary system of thought and language can be traced to Michael Reddy's (this volume) now classic paper, The Conduit Metaphor, which first appeared in the first edition of this collection. Reddy did far more in that paper than he modestly suggested. With a single, thoroughly analyzed example, he allowed us to see, albeit in a restricted domain, that ordinary everyday English is largely metaphorical, dispelling once and for all the traditional view that metaphor is primarily in the realm of poetic or figurative language. Reddy showed, for a single very significant case, that the locus of metaphor is thought, not language, that metaphor is a major and indispensable part of our ordinary, conventional way of conceptualizing the world, and that our everyday behavior reflects our metaphorical understanding of experience. Though other theorists had noticed some of these characteristics of metaphor, Reddy was the first to demonstrate it by rigorous linguistic analysis, stating generalizations over voluminous examples. Reddy's chapter on how we conceptualize the concept of communication by metaphor gave us a tiny glimpse of an enormous system of conceptual metaphor. Since its appearance, an entire branch of linguis tics and cognitive science has developed to study systems of metaphorical thought that we use to reason, that we base our actions on, and that underlie a great deal of the structure of language. The bulk of the chapters in this book were written before the development of the contemporary field of metaphor research. My chapter will therefore contradict much that appears in the others, many of which make certain assumptions that were widely taken for granted in 1977. A major assumption that is challenged by contemporary research is the traditional division between literal and figurative language, with metaphor as a kind of figurative language. This entails, by definition, that: What is literal is not metaphorical. In fact, the word literal has traditionally been used with one or more of a set of assumptions that have since proved to be false:

\section{Traditional false assumptions}

- All everyday conventional language is literal, and none is metaphorical.

- All subject matter can be comprehended literally, without metaphor.

- Only literal language can be contingently true or false.

- All definitions given in the lexicon of a language are literal, not metaphorical.

- The concepts used in the grammar of a language are all literal; none are metaphorical. 
The big difference between the contemporary theory and views of metaphor prior to Reddy's work lies in this set of assumptions. The reason for the difference is that, in the intervening years, a huge system of everyday, convention al, conceptual metaphors has been discovered. It is a system of metaphor that structures our everyday conceptual system, including most abstract concepts, and that lies behind much of everyday language. The discovery of this enormous metaphor system has destroyed the traditional literal-figurative distinction, since the term literal, as used in defining the traditional distinction, carries with it all those false assumptions. A major difference between the contemporary theory and the classical one is based on the old literal-figurative distinction. Given that distinction, one might think that one arrives at a metaphorical interpretation of a sentence by starting with the literal meaning and applying some algorithmic process to it (see Searle, this volume). Though there do exist cases where something like this happens, this is not in general how metaphor works, as we shall see shortly.

\section{What is not metaphorical}

Although the old literal-metaphorical distinction was based on assumptions that have proved to be false, one can make a different sort of literal-metaphorical distinction: those concepts that are not comprehended via conceptual metaphor might be called literal. Thus, while I will argue that a great many common concepts like causation and purpose are metaphorical, there is nonetheless an extensive range of nonmetaphorical concepts. Thus, a sentence like The balloon went up is not metaphorical, nor is the old philosopher's favorite The cat is on the mat. But as soon as one gets away from concrete physical experience and starting talking about abstractions or emotions, metaphorical understanding is the norm.

\section{The Contemporary Theory: Some Examples}

Let us now turn to some examples that are illustrative of contemporary metaphor research. They will mostly come from the domain of everyday conventional metaphor, since that has been the main focus of the research. I will turn to the discussion of poetic metaphor only after I have discussed the conventional system, since knowledge of the conventional system is needed to make sense of most of the poetic cases. The evidence for the existence of a system of conventional conceptual metaphors is of five types:

-Generalizations governing polysemy, that is, the use of words with a number of related meanings.

-Generalizations governing inference patterns, that is, cases where a pattern of inferences from one conceptual domain is used in another domain.

-Generalizations governing novel metaphorical language (see, Lakoff \& Turner, 1989).

-Generalizations governing patterns of semantic change (see, Sweetser, 1990).

-Psycholinguistic experiments (see, Gibbs, 1990, this volume).

We will primarily be discussing the first three of these sources of evidence, since they are the most robust. 


\section{Conceptual Metaphor}

Imagine a love relationship described as follows: Our relationship has hit a dead-end street.

Here love is being conceptualized as a journey, with the implication that the relationship is stalled, that the lovers cannot keep going the way they've been going, that they must turn back, or abandon the relationship altogether. This is not an isolated case. English has many everyday expressions that are based on a conceptualization of love as a journey, and they are used not just for talking about love, but for reasoning about it as well. Some are necessarily about love; others can be understood that way: Look how far we've come. It's been a long, bumpy road. We can't turn back now. We're at a crossroads. We may have to go our separate ways. The relationship isn't going anywhere. We're spinning our wheels. Our relationship is off the track. The marriage is on the rocks. We may have to bail out of this relationship. These are ordinary, everyday English expressions. They are not poetic, nor are they necessarily used for special rhetorical effect. Those like Look how far we've come, which aren't necessarily about love, can readily be understood as being about love. As a linguist and a cognitive scientist, I ask two commonplace questions:

- Is there a general principle governing how these linguistic expressions about journeys are used to characterize love?

- Is there a general principle governing how our patterns of inference about journeys are used to reason about love when expressions such as these are used?

The answer to both is yes. Indeed, there is a single general principle that answers both questions. But it is a general principle that is neither part of the grammar of English, nor the English lexicon. Rather, it is part of the conceptual system underlying English: It is a principle for under standing the domain of love in terms of the domain of journeys. The principle can be stated informally as a metaphorical scenario: The lovers are travelers on a journey together, with their common life goals seen as destinations to be reached. The relationship is their vehicle, and it allows them to pursue those common goals together. The relationship is seen as fulfilling its purpose as long as it allows them to make progress toward their common goals. The journey isn't easy. There are impediments, and there are places (crossroads) where a decision has to be made about which direction to go in and whether to keep traveling together. The metaphor involves understanding one domain of experience, love, in terms of a very different domain of experience, journeys. More technically, the metaphor can be understood as a mapping (in the mathematical sense) from a source domain (in this case, journeys) to a target domain (in this case, love). The mapping is tightly structured. There are ontological correspondences, according to which entities in the domain of love (e.g., the lovers, their common goals, their difficulties, the love relationship, etc.) correspond systematically to entities in the domain of a journey (the travelers, the vehicle, des tinations, etc.). To make it easier to remember what mappings there are in the conceptual system, Johnson and I (lakoff and Johnson, 1980) adopted a strategy for naming such mappings, using mnemonics which suggest the mapping. Mnemonic names typically (though not always) have the form: TARGETDOMAIN IS SOURCE-DOMAIN, or alternatively, TARGET-DOMAIN AS SOURCEDOMAIN. In this case, the name of the mapping is LOVE IS A JOURNEY. When I speak of the LOVE IS A JOURNEY metaphor, I am using a mnemonic for a set of ontological correspondences that characterize a map ping, namely:

\section{THE LOVE-AS-JOURNEY MAPPING}

-The lovers correspond to travelers. 
-The love relationship corresponds to the vehicle.

-The lovers' common goals correspond to their common destinations on the journey.

-Difficulties in the relationship correspond to impediments to travel.

It is a common mistake to confuse the name of the mapping, LOVE IS A JOURNEY, for the mapping itself. The mapping is the set of correspondences. Thus, whenever I refer to a metaphor by a mnemonic like LOVE IS A JOURNEY, I will be referring to such a set of correspondences. If mappings are confused with names of mappings, another misunderstanding can arise. Names of mappings commonly have a propositional form, for example, LOVE IS A JOURNEY. But the mappings themselves are not propositions. If mappings are confused with names for mappings, one might mistakenly think that, in this theory, metaphors are propositional. They are, of course, anything but that: metaphors are mappings, that is, sets of conceptual correspondences. The LOVE-AS-JOURNEY mapping is a set of ontological correspondences that characterize epistemic correspondences by mapping knowledge about journeys onto knowledge about love. Such correspondences permit us to reason about love using the knowledge we use to reason about journeys. Let us take an example. Consider the expression, We're stuck, said by one lover to another about their relationship. How is this expression about travel to be understood as being about their relationship? We're stuck can be used of travel, and when it is, it evokes knowledge about travel. The exact knowledge may vary from person to person, but here is a typical example of the kind of knowledge evoked. The capitalized expressions represent entities $\mathrm{n}$ the ontology of travel, that is, in the source domain of the LOVE IS A JOURNEY mapping given above. Two TRAVELLERS are in a VEHICLE, TRAVELING WITH COMMON DESTINATIONS. The VEHICLE encounters some IMPEDIMENT and gets stuck, that is, makes it nonfunctional. If they do nothing, they will not REACH THEIR DESTINATIONS. There are a limited number of alternatives for action:

- They can try to get it moving again, either by fixing it or get ting it past the IMPEDIMENT that stopped it.

- They can remain in the nonfunctional VEHICLE and give up on REACHING THEIR DESTINATIONS.

- They can abandon the VEHICLE.

- The alternative of remaining in the nonfunctional VEHICLE takes the least effort, but does not satisfy the desire to REACH THEIR DESTINATIONS.

The ontological correspondences that constitute the LOVE IS A JOURNEY metaphor map the ontology of travel onto the ontology of love. In doing so, they map this scenario about travel onto a corresponding love scenario in which the corresponding alternatives for action are seen. Here is the corresponding love scenario that results from applying the correspondences to this knowledge structure. The target domain entities that are mapped by the correspondences are capitalized:

Two LOVERS are in a LOVE RELATIONSHIP, PURSUING COMMON LIFE GOALS. The RELATIONSHIP encounters some DIFFICULTY, which makes it nonfunctional. If they do nothing, they will not be able to ACHIEVE THEIR LIFE GOALS. There are a limited number of alternatives for action:

- They can try to get it moving again, either by fixing it or getting it past the DIFFICULTY.

- They can remain in the nonfunctional RELATIONSHIP, and give up on 
ACHIEVING THEIR LIFE GOALS.

- $\quad$ They can abandon the RELATIONSHIP.

The alternative of remaining in the nonfunctional RELATIONSHIP takes the least effort, but does not satisfy the desire to ACHIEVE LIFE GOALS. This is an example of an inference pattern that is mapped from one domain to another. It is via such mappings that we apply knowledge about travel to love relationships.

\section{Metaphors are not mere words}

What constitutes the LOVE-AS-JOURNEY metaphor is not any particular word or expression. It is the ontological mapping across conceptual domains, from the source domain of journeys to the target domain of love. The metaphor is not just a matter of language, but of thought and reason. The language is secondary. The mapping is primary, in that it sanctions the use of source domain language and inference patterns for target domain concepts. The mapping is conventional, that is, it is a fixed part of our conceptual system, one of our conventional ways of conceptualizing love relationships. This view of metaphor is thoroughly at odds with the view that metaphors are just linguistic expressions. If metaphors were merely linguistic expressions, we would expect different linguistic expressions to be different metaphors. Thus, "We've hit a dead-end street" would constitute one metaphor. "We can't turn back now" would constitute another, entirely different metaphor. "Their marriage is on the rocks" would involve still a different metaphor. And so on for dozens of examples. Yet we don't seem to have dozens of different metaphors here. We have one metaphor, in which love is conceptualized as a journey. The mapping tells us precisely how love is being conceptualized as a journey. And this unified way of conceptualizing love metaphorically is realized in many different linguistic expressions. It should be noted that contemporary metaphor theorists commonly use the term metaphor to refer to the conceptual mapping, and the term metaphorical expression to refer to an individual linguistic expression (like dead-end street) that is sanctioned by a mapping. We have adopted this terminology for the following reason: Metaphor, as a phenomenon, involves both conceptual mappings and individual linguistic expressions. It is important to keep them distinct. Since it is the mappings that are primary and that state the generalizations that are our principal concern, we have reserved the term metaphor for the mappings, rather than for the linguistic expressions. In the literature of the field, small capitals like LOVE IS A JOURNEY are used as mnemonics to name mappings. Thus, when we refer to the LOVE IS A JOURNEY metaphor, we are refering to the set of correspondences discussed above. The English sentence Love is a journey, on the other hand, is a metaphorical expression that is understood via that set of correspondences.

\section{Generalizations}

The LOVE IS A JOURNEY metaphor is a conceptual mapping that characterizes a generalization of two kinds:

- Polysemy generalization: A generalization over related senses of linguistic expressions, e.g., dead-end street, crossroads, stuck, spinning one's wheels, not going anywhere, and so on.

- Inferential generalization: A generalization over inferences across different conceptual domains. 
That is, the existence of the mapping provides a general answer to two questions: -Why are words for travel used to describe love relationships? -Why are inference patterns used to reason about travel also used to reason about love relationships. Correspondingly, from the perspective of the linguistic analyst, the existence of such cross-domain pairings of words and of inference patterns provides evidence for the existence of such mappings.

\section{Novel extensions of conventional metaphors}

The fact that the LOVE IS A JOURNEY mapping is a fixed part of our conceptual system explains why new and imaginative uses of the mapping can be understood instantly, given the ontological correspondences and other knowledge about journeys. Take the song lyric, We're driving in the fast lane on the freeway of love. The traveling knowledge called upon is this: When you drive in the fast lane, you go a long way in a short time and it can be exciting and dangerous. The general metaphorical mapping maps this knowledge about driving into knowledge about love relationships. The danger may be to the vehicle (the relationship may not last) or the passengers (the lovers may be hurt, emotionally). The excitement of the love-journey is sexual. Our understanding of the song lyric is a consequence of the pre-existing metaphorical correspondences of the LOVE-ASJOURNEY metaphor. The song lyric is instantly comprehensible to speakers of English because those metaphorical correspondences are already part of our conceptual system. The LOVE-AS-JOURNEY metaphor and Reddy's Conduit Metaphor were the two examples that first convinced me that metaphor was not a figure of speech, but a mode of thought, defined by a systematic mapping from a source to a target domain. What convinced me were the three characteristics of metaphor that I have just discussed: The systematicity in the linguistic correspondences. The use of metaphor to govern reasoning and behavior based on that reasoning. The possibility for understanding novel extensions in terms of the conventional correspondences.

\section{Motivation}

Each conventional metaphor, that is, each mapping, is a fixed pattern of conceptual correspondences across conceptual domains. As such, each mapping defines an openended class of potential correspondences across inference patterns. When activated, a mapping may apply to a novel source domain knowledge structure and characterize a corresponding target domain knowledge structure. Mappings should not be thought of as processes, or as algorithms that mechanically take source domain inputs and produce target domain outputs. Each mapping should be seen instead as a fixed pattern of onotological correspondences across domains that may, or may not, be applied to a source domain knowledge structure or a source domain lexical item. Thus, lexical items that are conventional in the source domain are not always conventional in the target domain. Instead, each source domain lexical item may or may not make use of the static mapping pattern. If it does, it has an extended lexicalized sense in the target domain, where that sense is characterized by the mapping. If not, the source domain lexical item will not have a conventional sense in the target domain, but may still be actively mapped in the case of novel metaphor. Thus, the words freeway and fast lane are not conventionally used of love, but the knowledge structures associated with them are mapped by the LOVE IS A JOURNEY metaphor in the case of We're driving in the fast lane on the freeway of love.

\section{Imageable Idioms}

Many of the metaphorical expressions discussed in the literature on conventional metaphor are idioms. On classical views, idioms have arbitrary meanings. But within 
cognitive linguistics, the possibility exists that they are not arbitrary, but rather motivated. That is, they do arise automatically by productive rules, but they fit one or more patterns present in the conceptual system. Let us look a little more closely at idioms. An idiom like spinning one's wheels comes with a conventional mental image, that of the wheels of a car stuck in some substance-either in mud, sand, snow, or on ice, so that the car cannot move when the motor is engaged and the wheels turn. Part of our knowledge about that image is that a lot of energy is being used up (in spinning the wheels) without any progress being made, that the situation will not readily change of its own accord, that it will take a lot of effort on the part of the occupants to get the vehicle moving again --and that may not even be possible. The love-as-journey metaphor applies to this knowledge about the image. It maps this knowledge onto knowledge about love relationships: A lot of energy is being spent without any progress toward fulfilling common goals, the situation will not change of its own accord, it will take a lot of effort on the part of the lovers to make more progress, and so on. In short, when idioms that have associated conventional images, it is common for an independently-motivated conceptual metaphor to map that knowledge from the source to the target domain. For a survey of experiments verifying the existence of such images and such mappings, see Gibbs 1990 and this volume.

\section{Mappings are at the superordinate level}

In theLOVE IS A JOURNEY mapping, a love relationship corresponds to a vehicle. A vehicle is a superordinate category that includes such basic-level categories as car, train, boat, and plane. Indeed, the examples of vehicles are typically drawn from this range of basic level categories: car ( long bumpy road, spinning our wheels), train (off the track), boat (on the rocks, foundering), plane (just taking off, bailing out). This is not an accident: in general, we have found that mappings are at the superordinate rather than the basic level. Thus, we do not find fully general submappings like A LOVE RELATIONSHIP IS A $C A R$; when we find a love relationship conceptualized as a car, we also tend to find it conceptualized as a boat, a train, a plane, etc. It is the superordinate category VEHICLE not the basic level category CAR that is in the general mapping. It should be no surprise that the generalization is at the superordinate level, while the special cases are at the basic level. After all, the basic level is the level of rich mental images and rich knowledge structure. (For a discussion of the properties of basic-level categories, see Lakoff, 1987, pp. 31-50.) A mapping at the superordinate level maximizes the possibilities for mapping rich conceptual structure in the source domain onto the target domain, since it permits many basic-level instances, each of which is information rich. Thus, a prediction is made about conventional mappings: the categories mapped will tend to be at the superordinate rather than basic level. Thus, one tends not to find mappings like A LOVE RELATIONSHIP IS A CAR or A LOVE RELATIONSHIP IS A BOAT. Instead, one tends to find both basic-level cases (e.g., both cars and boats), which indicates that the generalization is one level higher, at the superordinate level of the vehicle. In the hundreds of cases of conventional mappings studied so far, this prediction has been borne out: it is superordinate categories that are used in mappings.

\section{Basic Semantic Concepts That Are Metaphorical}

Most people are not too surprised to discover that emotional concepts like love and anger are understood metaphorically. What is more interesting, and I think more exciting, is the realization that many of the most basic concepts in our conceptual systems are also 
comprehended normally via metaphor-concepts like time, quantity, state, change, action, cause, purpose, means, modality and even the concept of a category. These are concepts that enter normally into the grammars of languages, and if they are indeed metaphorical in nature, then metaphor becomes central to grammar. What I would like to suggest is that the same kinds of considerations that lead to our acceptance of the LOVE-AS-JOURNEY metaphor lead inevitably to the conclusion that such basic concepts are often, and perhaps always, understood via metaphor.

\section{Categories}

Classical categories are understood metaphorically in terms of bounded regions, or 'containers.' Thus, something can be in or out of a category, it can be put into a category or removed from a category, etc. The logic of classical categories is the logic of containers (see figure 1). If $\mathrm{X}$ is in container $\mathrm{A}$ and container $\mathrm{A}$ is in container $\mathrm{B}$, then $\mathrm{X}$ is in container B. This is true not by virtue of any logical deduction, but by virtue of the topological properties of containers. Under the CLASSICAL CATEGORIES ARE CONTAINERS metaphor, the logical properties of categories are inherited from the logical properties of containers. One of the principal logical properties of classical categories is that the classical syllogism holds for them. The classical syllogism, Socrates is a man. All men are mortal. Therefore, Socrates is mortal. is of the form: If $\mathrm{X}$ is in category $\mathrm{A}$ and category $\mathrm{A}$ is in category $\mathrm{B}$, then $\mathrm{X}$ is in category $\mathrm{B}$. Thus, the logical properties of classical categories can be seen as following from the topological properties of containers plus the metaphorical mapping from containers to categories. As long as the topological properties of containers are preserved by the mapping, this result will be true. In other words, there is a generalization to be stated here. The language of containers applies to classical categories and the logic of containers is true of classical categories. A single metaphorical mapping ought to characterize both the linguistic and logical generalizations at once. This can be done provided that the topological properties of containers are preserved in the mapping. The joint linguistic-and-inferential relation between containers and classical categories is not an isolated case. Let us take another example.

\section{Quantity and Linear Scales}

The concept of quantities involves at least two metaphors. The first is the well-known MORE IS UP, LESS IS DOWN metaphor as shown by a myriad of expressions like Prices rose, Stocks skyrocketed, The market plummeted, and so on. A second is that LINEAR SCALES ARE PATHS. We can see this in expressions like: John is far more intelligent than Bill. John's intelligence goes way beyond Bill's. John is way ahead of Bill in intelligence. The metaphor maps the starting point of the path onto the bottom of the scale and maps distance traveled onto quantity in general. What is particularly interesting is that the logic of paths maps onto the logic of linear scales. (See figure 2.) Path inference: If you are going from $\mathrm{A}$ to $\mathrm{C}$, and you are now at in intermediate point $\mathrm{B}$, then you have been at all points between A and B and not at any points between B and C. Example: If you are going from San Francisco to N.Y. along route 80, and you are now at Chicago, then you have been to Denver but not to Pittsburgh. Linear scale inference: If you have exactly $\$ 50$ in your bank account, then you have $\$ 40, \$ 30$, and so on, but not $\$ 60, \$ 70$, or any larger amount. The form of these inferences is the same. The path inference is a consequence of the cognitive topology of paths. It will be true of any path image-schema. Again, there is a linguistic-and-inferential generalization to be stated. It would be stated by the metaphor LINEAR SCALES ARE PATHS, provided that metaphors in general preserve the cognitive topology (that is, the image-schematic structure) of the source 
domain. Looking at the inferential structure alone, one might suggest a nonmetaphorical alternative in which both linear scales and paths are instances of a more general abstract schema. But when both the inferential and lexical data are considered, it becomes clear that a metaphorical solution is required. An expression like ahead of is from the spatial domain, not the linear scale domain: ahead in its core sense is defined with respect to one's head-it is the direction in which one is facing. To say that there is no metaphorical mapping from paths to scales is to say that ahead of is not fundamentally spatial and characterized with respect to heads; it is to claim rather that ahead is very abstract, neutral between space and linear scales, and has nothing to do with heads. This would be a bizarre analysis. Similarly, for sentences like John's intelligence goes beyond Bill's, the nonmetaphorical analysis would claim that $g o$ is not fundamentally a verb of motion at all, but is somehow neutral between motion and a linear relation. This would also be bizarre. In short, if one grants that ahead of and go are fundamentally spatial, then the fact that they can also be used of linear scales suggests a metaphor solution. Indeed, there could be no such neutral sense of go for these cases, since go beyond in the spatial sense involves motion, while in the linear scale sense, there is no motion or change, but just a point on a scale. Here the neutral case solution is not even available.

\section{The Invariance Principle}

In the examples we have just considered, the image-schemas characterizing the source domains (containers, paths) are mapped onto the target domains (categories, linear scales). This observation leads to the following hypothesis, called The Invariance Principle:

Metaphorical mappings preserve the cognitive topology (that is, the image-schema structure) of the source domain, in a way consistent with the inherent structure of the target domain. What the Invariance Principle does is guarantee that, for container schemas, interiors will be mapped onto interiors, exteriors onto exteriors, and boundaries onto boundaries; for path-schemas, sources will be mapped onto sources, goals onto goals, trajectories onto trajectories; and so on. To understand the Invariance Principle properly, it is important not to think of mappings as algorithmic processes that start with source domain structure and wind up with target domain structure. Such a mistaken understanding of mappings would lead to a mistaken understanding of the Invariance Principle, namely, that one first picks all the image-schematic structure of the source domain, then one copies it onto the target domain unless the target domain interferes. One should instead think of the Invariance Principle in terms of constraints on fixed correspondences: If one looks at the existing correspondences, one will see that the Invariance Principle holds: source domain interiors correspond to target domain interiors; source domain exteriors correspond to target domain exteriors; etc. As a consequence it will turn out that the image-schematic structure of the target domain cannot be violated: One cannot find cases where a source domain interior is mapped onto a target domain exterior, or where a source domain exterior is mapped onto a target domain path. This simply does not happen.

\section{Target domain overrides}

A corollary of the Invariance Principle is that image-schema structure inherent in the target domain cannot be violated, and that inherent target domain structure limits the possibilities for mappings automatically. This general principle explains a large number of previously mysterious limitations on metaphorical mappings. For example, it explains why you can give someone a kick, even if they don't have it afterwards, and why you can give someone information, even if you don't lose it. This is just a consequence of the fact 
that inherent target domain structure automatically limits what can be mapped. For example, consider that part of your inherent knowledge of actions that says that actions do not continue to exist after they occur. Now consider the ACTIONS ARE TRANSFERS metaphor, in which actions are conceptualized as objects transferred from an agent to a patient, as when one gives someone a kick or a punch. We know (as part of target domain knowledge) that an action does not exist after it occurs. In the source domain, where there is a giving, the recipient possesses the object given after the giving. But this cannot be mapped onto the target domain since the inherent structure of the target domain says that no such object exists after the action is over. The target domain override in the Invariance Principle explains why you can give someone a kick without his having it afterward.

\section{Abstract inferences as metaphorical spatial inferences}

Spatial inferences are characterized by the topological structure of image-schemas. We have seen cases such as CATEGORIES ARE CONTAINERS and LINEAR SCALES ARE PATHS where image-schema structure is preserved by metaphor and where abstract inferences about categories and linear scales are metaphorical versions of spatial inferences about containers and paths. The Invariance Principle hypothesizes that imageschema structure is always preserved by metaphor. The Invariance Principle raises the possibility that a great many, if not all, abstract inferences are actually metaphorical versions of spatial inferences that are inherent in the topological structure of imageschemas. What I will do now is turn to other cases of basic, but abstract, concepts to see what evidence there is for the claim that such concepts are fundamentally characterized by metaphor.

\section{Time}

It has often been noted that time in English is conceptualized in terms of space. The details are rather interesting. Ontology: Time is understood in terms of things (i.e., entities and locations) and motion. Background condition: The present time is at the same location as a canonical observer.

Mapping:

- Times are things.

- The passing of time is motion.

- Future times are in front of the observer; past times are behind the observer.

- One thing is moving, the other is stationary; the stationary entity is the deictic center.

Entailment:

-Since motion is continuous and one-dimensional, the passage of time is continuous and one-dimensional.

Special case 1:

-The observer is fixed; times are entities moving with respect to the observer.

Times are oriented with their fronts in their direction of motion.

Entailments: 
-If time 2 follows time 1 , then time 2 is in the future relative to time 1.

The time passing the observer is the present time.

Time has a velocity relative to the observer.

Special case 2:

Times are fixed locations; the observer is moving with respect to time.

Entailment:

-Time has extension, and can be measured. $<$

A extended time, like a spatial area, may be conceived of as a bounded region.

This metaphor, TIME PASSING IS MOTION, with its two special cases, embodies a generalization that accounts for a wide range of cases where a spatial expression can also be used for time. Special case 1, TIME PASSING IS MOTION OF AN $O B J E C T$, accounts for both the linguistic form and the semantic entailments of expressions like: The time will come when... The time has long since gone when ... The time for action has arrived. That time is here. In the weeks following next Tuesday.... On the preceding day, ... I'm looking ahead to Christmas. Thanksgiving is coming up on us. Let's put all that behind us. I can't face the future. Time is flying by. The time has passed when ... Thus, special case 1 characterizes the general principle behind the temporal use of words like come, go, here, follow, precede, ahead, behind, fly, pass, accounting not only for why they are used for both space and time, but why they mean what they mean.

Special case 2, TIME PASSING IS MOTION OVER A LANDSCAPE, accounts for a different range of cases, expressions like:

- There's going to be trouble down the road.

- He stayed there for ten years.

- He stayed there a long time.

- His stay in Russia extended over many years.

- He passed the time happily.

- He arrived on time.

- We're coming up on Christmas.

- We're getting close to Christmas.

- He'll have his degree within two years.

- I'll be there in a minute.

Special case 2 maps location expressions like down the road, for + location, long, over, come, close to, within, in, pass, onto corresponding temporal expressions with their corresponding meanings. Again, special case 2 states a general principle relating spatial terms and inference patterns to temporal terms and inference patterns. The details of the two special cases are rather different; indeed, they are inconsistent with one another. The existence of such special cases has an especially interesting theoretical consequence: words mapped by both special cases will have inconsistent readings. Take, for example, the come of Christmas is 
coming (special case 1) and We're coming up on Christmas (special case 2). Both instances of come are temporal, but one takes a moving time as first argument and the other takes a moving observer as first argument. The same is true of pass in The time has passed (special case 1) and in He passed the time (special case 2). These differences in the details of the mappings show that one cannot just say blithely that spatial expressions can be used to speak of time, without specifying details, as though there were only one correspondence between time and space. When we are explicit about stating the mappings, we discover that there are two different-and inconsistent-subcases. The fact that time is understood metaphorically in terms of motion, entities, and locations accords with our biological knowledge. In our visual systems, we have detectors for motion and detectors for objects/locations. We do not have detectors for time (whatever that could mean). Thus, it makes good biological sense that time should be understood in terms of things and motion.

\section{Duality}

The two special cases (location and object) of TIME PASSING IS MOTION metaphor is not merely an accidental feature of our understanding of time. As we shall see below, there are other metaphors that come in such location-object pairs. Such pairs are called duals, and the general phenomenon in which metaphors come in location-object pairs is referred to as duality.

\section{Simultaneous mappings}

It is important to recall that metaphorical mappings are fixed correspondences that can be activated, rather than algorithmic processes that take inputs and give outputs. Thus, it is not the case that sentences containing conventional metaphors are the products of a real-time process of conversion from literal to metaphorical readings. A sentence like The time for action has arrived is not understood by first trying to give a literal reading to arrive, and then, upon failing, trying to give it a temporal reading. Instead, the metaphor TIME PASSING IS MOTION is a fixed structure of existing correspondences between the space and time domains, and arrive has a conventional extended meaning that makes use of that fixed structure of correspondences. Thus, it is possible for two different parts of a sentence to make use of two distinct metaphorical mappings at once. Consider a phrase like, Within the coming weeks. Here, within makes uses of the metaphor of time as a stationary landscape which has extension and bounded regions, while coming makes use of the metaphor of times as moving objects. This is possible because the two metaphors for time pick out different aspects of the target domain. The coming weeks conceptualizes those weeks as a whole, in motion relative to the observer. Within looks inside that whole, conceptualizing it as a bounded region with an interior. Each mapping is used partially. Thus, while the mappings-as wholes-are inconsistent, there are cases where parts of the mappings may be consistently superimposed. The Invariance Principle allows such such parts of the mappings to be picked out and used to characterize reasoning about different aspects of the target domain. Simultaneous mappings are very common in poetry. Take, for example the Dylan Thomas line Do not go gentle into that good night. Here go reflects DEATH IS DEPARTURE, gentle reflects LIFE IS A STRUGGLE, with death as defeat. Night reflects A LIFETIME IS A DAY, with death as night. This one line has three different, metaphors for death, each mapped onto different 
parts of the sentence. This is possible since mappings are fixed correspondences. There is an important lesson to be learned from this example. In mathematics, mappings are static correspondences. In computer science, it is common to represent mathematical mappings by algorithmic processes that take place in real time. Researchers in information processing psychology and cognitive science also commonly represent mappings as real-time algorithmic procedures. Some researchers from these fields have mistakenly supposed that the metaphorical mappings we are discussing should also be represented as real-time, sequential algorithmic procedures, where the input to each metaphor is a literal meaning. Any attempt to do this will fail for the simultaneous mapping cases just discussed.

\section{Event Structure}

I now want to turn to some research by myself and some of my students (especially Sharon Fischler, Karin Myhre, and Jane Espenson) on the metaphorical understanding of event structure in English. What we have found is that various aspects of event structure, including notions like states, changes, processes, actions, causes, purposes, and means, are characterized cognitively via metaphor in terms of space, motion, and force. The general mapping we have found goes as follows:

\section{The Event Structure Metaphor}

- States are locations (bounded regions in space).

- Changes are movements (into or out of bounded regions).

- Causes are forces.

- Actions are self-propelled movements.

- Purposes are destinations.

- Means are paths (to destinations).

- Difficulties are impediments to motion.

- Expected progress is a travel schedule; a schedule is a virtual traveler, who reaches pre-arranged destinations at pre-arranged times.

- External events are large, moving objects.

- Long term, purposeful activities are journeys.

This mapping generalizes over an extremely wide range of expressions for one or more aspects of event structure. For example, take states and changes. We speak of being in or out of a state, of going into or out of it, of entering or leaving it, of getting to a state or emerging from it. This is a rich and complex metaphor whose parts interact in complex ways. To get an idea of how it works, consider the submapping Difficulties are impediments to motion. In the metaphor, purposive action is self-propelled motion toward a destination. A difficulty is something that impedes motion to such a destination. Metaphorical difficulties of this sort come in five types: blockages; features of the terrain; burdens; counterforces; lack of an energy source. Here are examples of each: Blockages: He got over his divorce. He's trying to get around the regulations. He went through the trial. We ran into a brick wall. We've got him boxed into a corner. Features of the terrain He's between a rock and a hard place. It's been uphill all the way. We've been bogged 
down. We've been hacking our way through a jungle of regulations. Burdens He's carrying quite a load. He's weighed down by lot of assignments. He's been trying to shoulder all the responsibility. Get off my back! Counterforces Quit pushing me around. She's leading him around by the nose. She's holding him back. Lack of an energy source I'm out of gas. We're running out of steam.

To see just how rich The Event Structure Metaphor is, consider some of its basic entailments:

- Manner of action is manner of motion.

- A different means for achieving a purpose is a different path.

- Forces affecting action are forces affecting motion.

- The inability to act is the inability to move.

- Progress made is distance traveled or distance from goal.

We will consider examples of each of these one by one, including a number of special cases.

Aids to Action are Aids to Motion

It is smooth sailing from here on in.

It's all downhill from here.

There's nothing in our way.

A Different Means of Achieving a Result is a Different Path.

Do it this way.

She did it the other way.

Do it any way you can.

However you want to go about it is fine with me.

Manner of Action is Manner of Motion

We are moving/running/skipping right along.

We slogged through it.

He is flailing around.

He is falling all over himself.

We are leaping over hurdles.

He is out of step.

He is in step.

Careful Action is Careful Motion

I'm walking on eggshells. 
He is treading on thin ice.

He is walking a fine line.

Speed of Action is Speed of Movement

He flew through his work.

He is running around.

It is going swimmingly.

Keep things moving at a good clip.

Things have slowed to a crawl.

She is going by leaps and bounds.

I am moving at a snail's pace.

Purposeful Action is Self-propelled Motion To a Destination

This has the following special cases:

Making Progress Is Forward Movement

We are moving ahead.

Let's forge ahead.

Let's keep moving forward.

We made lots of forward movement.

Amount of Progress is Distance Moved

We've come a long way.

We've covered lots of ground.

We've made it this far.

Undoing Progress is Backward Movement

We are sliding backward.

We are backsliding.

We need to backtrack.

It is time to turn around and retrace our steps.

Expected Progress is a Travel Schedule; A Schedule is a Virtual Traveler, who reaches pre-arranged destinations at pre-arranged times.

We're behind schedule on the project.

We got a head start on the project. 
I'm trying to catch up.

I finally got a little ahead.

Starting an Action is Starting out on a Path

We are just starting out.

We have taken the first step.

Success Is Reaching The End of the Path

We've reached the end.

We are seeing the light at the end of the tunnel.

We only have a short way to go.

The end is in sight.

The end is a long way off.

Lack of Purpose is Lack of Direction

He is just floating around.

He is drifting aimlessly.

He needs some direction.

Lack of Progress is Lack of Movement

We are at a standstill.

We aren't getting any place.

We aren`t going anywhere.

We are going nowhere with this.

External Events Are Large Moving Objects

Special Case 1: Things

How're things going?

Things are going with me.

Things are going against me these days.

Things took a turn for the worse.

Things are going my way.

Special Case 2: Fluids

You gotta go with the flow.

I'm just trying to keep my head above water. 
The tide of events... The winds of change.... The flow of history...

I'm trying to get my bearings.

He's up a creek without a paddle.

We're all in the same boat.

Special Case 3: Horses

Try to keep a tight rein on the situation.

Keep a grip on the situation.

Don't let things get out of hand.

Wild horses couldn't makeme go. <

Whoa! (said when things start to get out of hand)

Such examples provide overwhelming empirical support for the existence of the event structure metaphor. And the existence of that metaphor shows that the most common abstract concepts--TIME, STATE, CHANGE, CAUSATION, ACTION, PURPOSE and MEANS-- are conceptualized via metaphor. Since such concepts are at the very center of our conceptual systems, the fact that they are conceptualized metaphorically shows that

\section{Inheritance hierarchies}

Metaphorical mappings do not occur isolated from one another. They are sometimes organized in hierarchical structures, in which 'lower' mappings in the hierarchy inherit the structures of the 'higher' mappings.

Let us consider an example of a hierarchy with three levels: Level 1: The Event Structure Metaphor Level 2: A PURPOSEFUL LIFE IS JOURNEY Level 3:LOVE IS A JOURNEY; A CAREER IS A JOURNEY

To refresh your memory, recall: The Event Structure Metaphor

Target Domain:

Events

Source Domain: Space

- States are locations (bounded regions in space).

- Changes are movements (into or out of bounded regions).

- Causes are forces.

- Actions are self-propelled movements.

- Purposes are destinations.

- Means are paths to destinations.

- Difficulties are impediments to motion.

- Expected progress is a travel schedule; A schedule is a virtual traveler, 
who reaches pre-arranged destinations at pre-arranged times.

- External events are large, moving objects.

- Longterm, purposeful activities are journeys.

In our culture, life is assumed to be purposeful, that is, we are expected to have goals in life. In the Event Structure Metaphor, purposes are destinations and purposeful action is self-propelled motion toward a destination. A purposeful life is a longterm, purposeful activity, and hence a journey. Goals in life are destinations on the journey. The actions one takes in life are self-propelled movements, and the totality of one's actions form a path one moves along. Choosing a means to achieve a goal is choosing a path to a destination. Difficulties in life are impediments to motion. External events are large moving objects that can impede motion toward one's life goals. One's expected progress through life is charted in terms of a life schedule, which is conceptualized as a virtual traveler that one is expected to keep up with. In short, the metaphor A PURPOSEFUL LIFE IS A JOURNEY makes use of all the structure of the Event Structure Metaphor, since events in a life conceptualized as purposeful are subcases of events in general.

\section{A PURPOSEFUL LIFE IS A JOURNEY}

- Target Domain:Life

- Source Domain: Space

- The person leading a life is a traveler.

- Inherits Event Structure Metaphor, with:

- $\quad$ Events $=$ Significant Life Events

- $\quad$ Purposes = Life Goals

Thus we have expressions like:

He got a head start in life. He's without direction in his life.

I'm where I want to be in life.

I'm at a crossroads in my life.

He'll go places in life.

He's never let anyone get in his way.

He's gone through a lot in life.

Just as significant life events are special cases of events, so events in a love relationship are special cases of life events. Thus, the LOVE IS A JOURNEY metaphor inherits the structure of the LIFE IS A JOURNEY metaphor. What is special about the LOVE IS A JOURNEY metaphor, is that there are two lovers, who are travelers, and that the love relationship is a vehicle. The rest of the mapping is a consequence of inheriting the LIFE IS A JOURNEY metaphor. Because the lovers are in the same vehicle, they have common destinations, that is, common life goals. Relationship difficulties are impediments to travel. 
- Target Domain: Love

- Source Domain: Space

- The lovers are travelers.

- The love relationship is a vehicle.

- Inherits the LIFE IS A JOURNEY metaphor.

A career is another aspect of life that can be conceptualized as a journey. Here, because STATUS IS UP, a career is actually a journey upward. Career goals are special cases of life goals.

\section{A CAREER IS A JOURNEY}

- Target Domain: Career

- Source Domain: Space

- A careerist is a traveler.

- Status is up.

- Inherits LIFE IS A JOURNEY, with :

- $\quad$ Life goals $=$ Career Goals

- Ideal: To go as high, far, and fast as possible.

Examples include:

He clawed his way to the top.

He's over the hill.

She's on the fast track.

He's climbing the corporate ladder.

She's moving up in the ranks quickly.

This inheritance hierarchy accounts for a range of generalizations. First, there are generalizations about lexical items. Take the word crossroads. It's central meaning is in the domain of space. But it can be used in a metaphorical sense to speak of any extended activity, of one's life, of a love relationship, or of a career. I'm at a crossroads on this project. I'm at a crossroads in life. We're at a crossroads in our relationship. I'm at a crossroads in my career. The hierarchy allows one to state a general principal: that crossroads is extended lexically via the submetaphor of the Event Structure Metaphor that Longterm Purposeful Activities Are Journeys. All its other uses are automatically generated via the inheritance hierarchy. Thus, separate senses for each level of the hierarchy are not needed. The second generalization is inferential in character. Thus the understanding of difficulties as impediments to travel occurs not only in events in general, but also in a purposeful life, in a love relationship, and in a career. The inheritance hierarchy guarantees that this understanding of difficulties in life, love, and careers is a consequence of such an understanding of difficulties in events in general. The hierarchy also allows us to characterize lexical items whose meanings are more restricted: Thus, climbing the ladder refers only to careers, not to love relationships or to life in general. Such hierarchical organization is a very prominent feature of the 
metaphor system of English and other languages. So far we have found that the metaphors higher up in the hierarchy tend to be more widespread than those mappings at lower levels. Thus, the Event Structure Metaphor is very widespread (and may even be universal), while the metaphors for life, love, and careers are much more restricted culturally.

\section{Duality in the Event Structure System}

In our discussion of time metaphors, we noted the existence of an object-location duality. There were two related time metaphors. In both, the passage of time was understood in terms of relative motion between an observer and a time. In the object-dual, the observer is fixed and times are moving objects. In the locationdual, the opposite is true. The observer moves and times are fixed locations in a landscape. The event structure system that we have seen so far is based wholly on location. But there is another event structure system that is the dual of the one we have just discussed -- a system based on objects rather than locations. In both systems, CHANGE IS MOTION and CAUSES ARE FORCES that control motion. The difference is this: In the location system, change is the motion of the thingchanging to a new location or from an old one. In the object system, the thingchanging doesn't necessarily move. Change is instead the motion of an object to, or way from, the thing-changing. In addition, the object in motion is conceptualized as a possession and the thing-changing as a possessor. Change is thus seen as the acquisition or loss of an object. Causation is seen as giving or taking. Here are some examples:

- I have a headache. [The headache is a possession.]

- I got a headache. [Change is acquisition -- motion to]

- My headache went away. [Change is loss -- motion from]

- The noise gave me a headache. [Causation is giving -- motion to]

- The aspirin took away my headache. [Causation is taking -- motion from]

We can see the duality somewhat more clearly with a word like trouble:

- I'm in trouble. [Trouble is a location]

- I have trouble. [Trouble is an object that is possessed]

In both cases, trouble is being attributed to me, and in both cases, trouble is metaphorically conceptualized as being in the same place as me (co-location) -- in one case, because I possess the trouble-object and in the other case, because I am in the trouble-location. That is, attribution in both cases is conceptualized metaphorically as co-location. In I'm in trouble, trouble is a state. A state is an attribute that that is conceptualized as a location. Attributes (or properties) are like states, except that they are conceptualized as possessable objects. Thus, STATES ARE LOCATIONS and ATTRIBUTES ARE POSSESSIONS are duals, since possession and location are special cases of the same thing -- co-location -- and since states and attributes are also special cases of the same thing -- what can be attributed to someone. Given this, we can see that there is an object-version of the Event Structure Metaphor:

- Attributes are possessions 
- Changes are movements (of possessions, namely, acquisitions or losses)

- Causes are forces (controlling the movement of possessions, namely, giving or taking away) These are the duals of: -States are locations

- Changes are movements (to or from locations)

- Causes are forces (controlling movement to or from locations)

Similarly, ACTIONS ARE SELF-PROPELLED MOVEMENTS (to or from locations) has as its object-dual ACTIONS ARE SELF-CONTROLLED ACQUISITIONS OR LOSSES. Thus, there is a reason why one can take certain actions -- you can take a shower, or take a shot at someone, or take a chance. The submapping PURPOSES ARE DESTINATIONS also has a dual. Destinations are desired locations, and so the submapping can be rephrased as PURPOSES ARE DESIRED LOCATIONS, and ACHIEVING A PURPOSE IS REACHING A DESIRED LOCATION. Replacing location by object, we get the dual PURPOSES ARE DESIRED OBJECTS, and ACHIEVING A PURPOSE IS ACQUIRING A DESIRED OBJECT(or ridding oneself of an undesirable one). Here are some examples:

\section{ACHIEVING A PURPOSE IS ACQUIRING A DESIRED OBJECT}

They just handed him the job.

It's within my grasp.

It eluded me.

Go for it.

It escaped me.

It slipped through my hands.

He is pursuing a goal.

Reach for /grab all the gusto you can get.

Latch onto a good job.

Seize the opportunity.

He found success.

There is also a hierarchical structure in the object version of the Event Structure Metaphor. A special case of getting an object is getting an object to eat. Hence,

ACHIEVING A PURPOSE IS GETTING SOMETHING TO EAT All the good jobs have been gobbled up.

He's hungry for success.

The opportunity has me drooling.

This is a mouth-watering opportunity.

Traditional methods of getting things to eat are hunting, fishing, and agriculture. Each of these special cases can be used metaphorically to conceptualize achieving 
(or attempting to achieve) a purpose.

TRYING TO ACHIEVE A PURPOSE IS HUNTING

I'm hunting for a job.

I bagged a promotion.

The pennant is in the bag.

The typical way to hunt is to use projectiles (bullets, arrows, etc.)

I'm shooting for a promotion.

I'm aiming for a career in the movies.

I'm afraid I missed my chance.

TRYING TO ACHIEVE A PURPOSE IS FISHING

He's fishing for compliments.

I landed a promotion.

She netted a good job.

I've got a line out on a good used car.

It's time to fish or cut bait.

TRYING TO ACHIEVE A PURPOSE IS AGRICULTURE

It's time I reaped some rewards.

That job is a plum.

Those are the fruits of his labor.

The contract is ripe for the picking.

I will not try to survey all the dualities in the English metaphor system, but it is worth mentioning a few to see how subtle and pervasive dualities are. Take, for example, the LIFE IS A JOURNEY metaphor, in which goals in life are destinations, that is, desired locations to be reached. Since the dual of PURPOSES ARE DESTINATIONS is PURPOSES ARE DESIRED OBJECTS, the dual of LIFE IS A JOURNEY is a metaphor in which life is an activity through which one acquires desired objects. In this culture, the principle activity of this sort is business, and hence, LIFE IS A BUSINESS is the dual of LIFE IS A JOURNEY.

A PURPOSEFUL LIFE IS A BUSINESS

He has a rich life.

It's an enriching experience.

I want to get a lot of out of life.

He's going about the business of everyday life. 
It's time to take stock of my life.

Recall thatLOVE IS A JOURNEY is an extension of A PURPOSEFUL LIFE IS A JOURNEY. It happens that LOVE IS A JOURNEY has a dual that is an extension of the dual of A PURPOSEFUL LIFE IS A JOURNEY, which is $A$ PURPOSEFUL LIFE IS A BUSINESS. The dual of LOVE IS JOURNEY is LOVE IS A PARTNERSHIP, that is, a two-person business. Thus, we speak of lovers as partners; there are marriage contracts, and in a long-term love relationship the partners are expected to do their jobs and to share in both responsibilities (what they contribute to the relationship) and benefits (what they get out of it). Longterm love relationships fail under the same conditions as businesses fail -- when what the partners get out of the relationship is not worth what they put into it.

Duality is a newly-discovered phenomenon. The person who first discovered it in the event structure system was Jane Espenson, a graduate student at Berkeley who who stumbled upon it in the course ofher research on causation metaphors. Since Espenson's discovery, other extensive dualities have been found in the the English metaphor system. However, at present, it is not know just how extensive dualities are in English, or even whether they are all of the location-object type. At this point, I will leave off discussing the metaphor system of English, even though hundreds of other mappings have been described to date.

The major point to take away from this discussion is that metaphor resides for the most part in this huge, highly structured, fixed system. This system is anything but dead. Because it is conventional, it is used constantly and automatically, with neither effort nor awareness. Novel metaphor uses this system, and builds on it, but only rarely occurs independently of it. But, most interestingly, this system of metaphor seems to give rise to abstract reasoning, which appears to be based on spatial reasoning.

\section{Invariance Again}

The metaphors I have discussed primarily map three kinds of image-schemas:

1. containers

2. paths

3. force-images

Because of the complexity of the sub-cases and interactions, the details are intricate, to say the least. However, the Invariance Principle does make claims in each case as to what image-schemas get mapped onto target domains. I will not go through most of the details here, but so far as I can see, the claims made about inferential structure are reasonable ones. For example, the logic of force dynamics does seem to map, via the submapping CAUSES ARE FORCES, onto the logic of causation. The following are inferences from the logic of forces inherent in force dynamics:

- $\quad$-A stationary object will move only when force is applied to it; without force, it will not move.

- $\quad$ The application of force requires contact; thus, the applier of the force must be in spatial contiguity with the thing it moves. 
- $\quad$ The application of force temporally precedes motion, since inertia must be overcome before motion can take place.

These are among the classic inferential conditions on causation: spatial contiguity, temporal precedence, and that A caused B only if B wouldn't have happened without A. At this point, I would like to take up the question of what else the Invariance Principle would buy us. I will consider two cases that arose while Mark Turner and I were writing More Than Cool Reason (Lakoff \& Turner, 1989). The first concerns image-metaphors and the second, generic-level metaphors. But before I move on to those topics, I should point an important consequence of invariance. Johnson and I argued in Metaphors We Live By (Lakoff \& Johnson, 1980) that a complex propositional structure could be mapped by metaphor onto another domain. The main example we gave was ARGUMENT AS WAR. Kovecses and I, in our analysis of anger metaphors (Lakoff, 1987, case study 1, Kovecses, 1990), also argued that metaphors could map complex propositional structures. The Invariance Principle does not deny this, but it puts those claims in a very different light. Complex propositional structures involve concepts like time, states, changes, causes, purposes, quantity scales, and categories. If all of these abstract concepts are characterized metaphorically, then the Invariance Principle claims that what we had called propositional structure is really image-schematic structure. In other words: So-called propositional inferences arise from the inherent topological structure of the image-schemas mapped by metaphor onto concepts like time, states, changes, actions, causes, purposes, means, quantity, and categories. The reason that I have taken the trouble to discuss all those abstract concepts is to demonstrate this consequence of the Invariance Principle; namely, that what have been seen in the past as propositional inferences are really imagebased inferences. If the Invariance Principle is correct, it has a remarkable consequence, namely that: Abstract reasoning is a special case of imaged-based reasoning. Image-based reasoning is fundamental and abstract reasoning is image-based reasoning under metaphorical projections to abstract domains. To look for independent confirmation of the Invariance Principle, let us turn to image-metaphors.

\section{Novel Metaphors}

\section{Image Metaphors}

There is a class of metaphors that function to map one conventional mental image onto another. These contrast with the metaphors I have discussed so far, each of which maps one conceptual domain onto another, often with many concepts in the source domain mapped onto many corresponding concepts in the target domain. Image-metaphors, by contrast, are 'one-shot' metaphors: they map only one image onto one other image. Consider, for example, this poem from the Indian tradition:

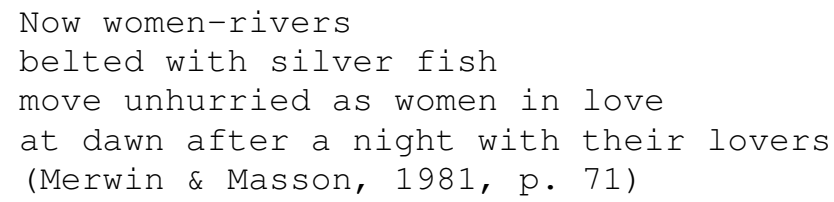

Here the image of the slow, sinuous walk of an Indian woman is mapped onto the image of the slow, sinuous, shimmering flow of a river. The shimmering of a school of fish is imagined as the shimmering of the belt. Metaphoric imagemappings work in just the same way as all other metaphoric mappings: by 
mapping the structure of one domain onto the structure of another. But here, the domains are conventional mental images. Take, for example, this line from Andre Breton: My wife . . . whose waist is an hourglass. This is a superimposition of the image of an hourglass onto the image of a woman's waist by virtue of their common shape. As before, the metaphor is conceptual; it is not in the words themselves, but in the mental images. Here, we have a mental image of an hourglass and of a woman, and we map the middle of the hourglass onto the waist of the woman. Note that the words do not tell us which part of the hourglass to map onto the waist, or even that it is only part of the hourglass shape that corresponds to the waist. The words are prompts for us to map from one conventional image to another. Similarly, consider: His toes were like the keyboard of a spinet. (Rabelais, 'The Descriptions of King Lent,' trans. J. M. Cohen) Here too, the words do not tell us that an individual toe corresponds to an individual key on the keyboard. Again, the words are prompts for us to perform a conceptual mapping between conventional mental images. In particular, we map aspects of the part-whole structure of one image onto aspects of the part-whole structure of another. Just as individual keys are parts of the whole keyboard, so individual toes are parts of the whole foot. Image-mapping can involve more than mapping physical part-whole relationships. For example, the water line of a river may drop slowly and that slowness is part of the dynamic image, which may be mapped onto the slow removal of clothing:

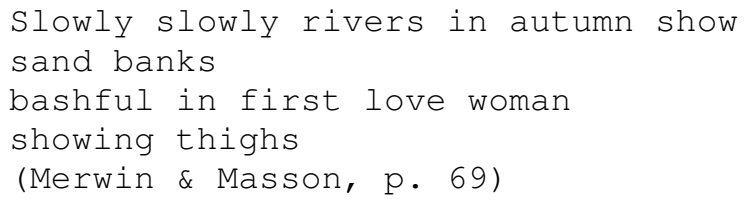

Other attributes are also mapped: the color of the sand bank onto the color of flesh, the quality of light on a wet sand bank onto the reflectiveness of skin, the light grazing of the water's touch receding down the bank onto the light grazing of the clothing along the skin. Notice that the words do not tell us that any clothing is involved. We get that from a conventional mental image. Part-whole structure is also mapped in this example. The water covers the hidden part of the bank just as the clothing covers the hidden part of the body. The proliferation of detail in the images limits image-mappings to highly specific cases. That is what makes them 'one-shot' mappings. Such mappings of one image onto another can lead us to map knowledge about the first image onto knowledge about the second. Consider the following example from the Navaho: My horse with a mane made of short rainbows. ('War God's Horse Song I' Words by Tall Kia ahni. Interpreted by Louis Watchman.) The structure of a rainbow, its band of curved lines for example, is mapped onto an arc of curved hair, and many rainbows onto many such arcs on the horse's mane. Such image-mapping allows us to map our evaluation of the source domain onto the target. We know that rainbows are beautiful, special, inspiring, larger than life, almost mystic, and that seeing them makes us happy and awe-inspired. This knowledge is mapped onto what we know of the horse: it too is awe-inspiring, beautiful, larger than life, almost mystic. This line comes from a poem containing a series of such image-mappings:

My horse with a hoof like a striped agate, with his fetlock like a fine eagle plume: my horse whose legs are like quick lightning whose body is an eagle-plumed arrow:

my horse whose tail is like a trailing black cloud. 
Image-metaphors raise two major issues for the general theory of metaphor:

How do they work?

What constrains the mappings?

What kind of internal structures do mental images have that permit some mappings to work readily, others only with effort, and others not at all?

What is the general theory of metaphor that unifies image-metaphors with all the conventional metaphors that map the propositional structure of one domain onto the propositional structure of another domain?

Turner and I (Lakoff and Turner, 1989) have suggested that the Invariance Principle could be an answer to both questions. We suggest that conventional mental images are structured by image-schemas and that image-metaphors preserve image-schematic structure, mapping parts onto parts and wholes onto wholes, containers onto containers, paths onto paths, and so on. The generalization would be that all metaphors are invariant with respect to their cognitive topology, that is, each metaphorical mapping preserves image-schema structure.

Generic-Level Metaphors

When Turner and I were writing More Than Cool Reason, we hypothesized the existence of what we called 'generic-level metaphors' to deal with two problems that we faced-first, the problem of personification and second, the problem of proverbs, which requires an understanding of analogy. I shall discuss each in turn.

\section{Personification.}

In studying a wide variety of poems about death in English, we found that, in poem after poem, death was personified in a relatively small number of ways: drivers, coachmen, footmen; reapers, devourers and destroyers; or opponents in a struggle or game (say, a knight or a chess opponent). The question we asked was: Why these? Why isn't death personified as a teacher or a carpenter or an ice cream salesman? Somehow, the ones that occur repeatedly seem appropriate. Why? In studying personifications in general, we found that the overwhelming number seem to fit a single pattern: events (like death) are understood in terms of actions by some agent (like reaping). It is that agent that is personified. We thus hypothesized a very general metaphor, EVENTS ARE ACTIONS, which combines with other, independently existing metaphors for life and death. Consider, for example, the DEATH IS DEPARTURE metaphor. Departure is an event. If we understand this event as an action on the part of some causal agent-someone who brings about, or helps to bring about, departure-then we can account for figures like drivers, coachmen, footmen, etc. Or take the PEOPLE ARE PLANTS metaphor. In the natural course of things, plants wither and die. But if we see that event as a causal action on the part of some agent, then that agent is a reaper. So far, so good. But why destroyers and devourers? And what about the impossible cases? Destruction and devouring are actions in which an entity ceases to exist. The same is true of death. The overall 'shape' of the event of death is similar in this respect to the overall 'shapes' of the events of destruction and devouring. Moreover, there is a causal aspect to death: the passage of time will eventually result in death. Thus, the overall shape of the event of death has an entity that over time ceases to exist as the result of some cause. Devouring and destruction have 
the same overall 'event-shape'. That is, it is the same with respect to causal structure and the persistence of entities over time. Turner (1987) had noticed a similar case in Death Is The Mother Of Beauty, his classic work on kinship metaphor. In expressions like Necessity is the mother of invention, or Edward Teller was the father of the H-bomb, causation is understood in terms of giving birth or fathering-what Turner called the CAUSATION IS PROGENERATION metaphor. But, as he observed (pp. 145-148), this metaphor could not be used for just any instance of causation. It could only be used for cases that had the overall event-shape of progeneration: something must be created out of nothing, and the thing created must persist for a long time (as if it had a life). Thus, for example, we can speak of Saussure as the father of modern synchronic linguistics, or of New Orleans as giving birth to jazz. But we cannot use this metaphor for a single causal action with a short-lived effect. Thus, we could not speak of Jose Canseco as the father of the home run he just hit, or of that home run as giving birth to the Oakland A's victory in the game. Though, of course, we could speak of Babe Ruth as the father of modern home-run hitting, and of the home runs giving birth to the era of baseball players as superstars. The overall event shape of the target domain limits the applicability of the metaphor. Recalling Turner's observation about CAUSATION IS PROGENERATION, we therefore hypothesized that EVENTS $A R E A C T I O N S$ is constrained in the following way: the action must have the same overall event-shape as the event. What is preserved across the mapping is the causal structure, the aspectual structure, and the persistence of entities. We referred to this as 'generic-level structure'. The preservation of generic-level structure explained why death is not metaphorized in terms of teaching, or filling the bathtub, or sitting on the sofa. They simply do not have the same causal and overall event structure, that is, they do not share 'generic-level structure.'

\section{Proverbs}

In Asian figures --proverbs in the form of short poems-- the question arises as to what are the limitations on the interpretation of a proverb. Some interpretations are natural; others seem impossible. Why? Consider the following example from Asian Figures, translated by William Merwin.

Blind

blames the ditch

To get some sense of the possible range of interpretations for such a proverb, consider the following application of the proverb: Suppose a presidential candidate knowingly commits some personal impropriety (though not illegal and not related to political issues) and his candidacy is destroyed by the press's reporting of the impropriety. He blames the press for reporting it, rather than himself for committing it. We think he should have recognized the realities of political press coverage when he chose to commit the impropriety. We express our judgment by saying, 'Blind / blames the ditch.' Turner and I (1989) observed that the knowledge structure used in comprehending the case of the candidate's impropriety shared certain things with the knowledge structure used in comprehending the literal interpretation of 'Blind / blames the ditch'. That knowledge structure is the following:

- There is a person with an incapacity, namely, blindness.

- He encounters a situation, namely a ditch, in which his incapacity, namely his inability to see the ditch, results in a negative consequence, namely, his 
falling into the ditch.

- He blames the situation, rather than his own incapacity.

- He should have held himself responsible, not the situation.

This specific knowledge schema about the blind man and the ditch is an instance of a general knowledge schema, in which specific information about the blindness and ditch are absent. Let us refer to it as the generic-level schema that structures our knowledge of the proverb. That generic-level knowledge schema is:

- There is a person with an incapacity.

- He encounters a situation in which his incapacity results in a negative consequence.

- He blames the situation rather than his own incapacity.

- He should have held himself responsible, not the situation.

This is a very general schema characterizing an open-ended category of situations. We can think of it as a variable template that can be filled in in many ways. As it happened, Turner and I were studying this at the time of the Gary Hart scandal, when Hart, a presidential candidate, committed certain sexual improprieties during a campaign, had his candidacy dashed, and then blamed the press for his downfall. Blind / blames the ditch fits this situation. Here's how:

- The person is the presidential candidate.

- His incapacity is his inability to understand the consequences of his personal improprieties.

- The context he encounters is his knowingly committing an impropriety and the press's reporting it.

- The consequence is having his candidacy dashed.

- He blames the press.

- We judge him as being foolish for blaming the press instead of himself.

If we view the generic-level schema as mediating between the proverb 'Blind / blames the ditch' and the story of the candidate's impropriety, we get the following correspondence:

- The blind person corresponds to the presidential candidate.

- His blindness corresponds to his inability to understand the consequences of his personal improprieties.

- Falling into the ditch corresponds to his committing the impropriety and having it reported.

- Being in the ditch corresponds to being out of the running as a candidate.

- Blaming the ditch corresponds to blaming the press coverage.

- Judging the blind man as foolish for blaming the ditch corresponds to judging the candidate as foolish for blaming the press coverage.

This correspondence defines the metaphorical interpretation of the proverb as applied to the candidate's impropriety. Moreover, the class of possible ways of filling in the generic-level schema of the proverb corresponds to the class of 
possible interpretations of the proverb. Thus, we can explain why 'Blind / blames the ditch' does not mean 'I took a bath' or 'My aunt is sitting on the sofa' or any of the myriad of things the proverb cannot mean. All of the proverbs that Turner and I studied turned out to involve this sort of generic-level schema. And the kinds of things that turned up in such schemas seemed to be pretty much the same in case after case. They include:

- Causal structure.

- Temporal structure.

- Event shape; that is, instantaneous or repeated, completed or open-ended, single or repeating, having fixed stages or not, preserving the existence of entities or not, and so on.

- Purpose structure.

- Modal structure.

- Linear Scales.

This is not an exhaustive list. But what it includes are most of the major elements of generic-level structure that we discovered. What is striking to us about this list is that everything on it is, under the Invariance Principle, an aspect of imageschematic structure. In short, if the Invariance Principle is correct, the way to arrive at a generic-level schema for some knowledge structure is to extract its image-schematic structure. The metaphoric interpretation of such discourse forms as proverbs, fables, allegories, and so on seems to depend on our ability to extract generic-level structure. Turner and I have called the relation between a specific knowledge structure and its generic-level structure the GENERIC IS SPECIFIC metaphor. It is an extremely common mechanism for comprehending the general in terms of the specific. If the Invariance Principle is correct, then the GENERIC IS SPECIFIC metaphor is a minimal metaphor that maps what the Invariance Principle requires it to and nothing more. Should it turn out to be the case that generic-level structure is exactly image-schematic structure, then the Invariance Principle would have enormous explanatory value. It would obviate the need for a separate characterization of generic-level structure. Instead, it would itself characterize generic-level structure-explaining possible personifications and the possible interpretations for proverbs.

\section{Analogy}

The GENERIC IS SPECIFIC metaphor is used for more than just the interpretation of proverbs. Turner (1991) has suggested that it is also the general mechanism at work in analogic reasoning, and that the Invariance Principle characterizes the class of possible analogies. We can see how this works with the Gary Hart example cited above. We can convert that example into an analogy with the following sentence: Gary Hart was like a blind man who fell into a ditch and blamed the ditch. The mechanism for understanding this analogy makes use of:

- a knowledge schema for the blind man and the ditch

- a knowledge schema concerning Gary Hart

- the GENERIC IS SPECIFIC metaphor The GENERIC IS SPECIFIC metaphor maps the knowledge schema for the blind man and the ditch into its generic-level schema. The generic-level schema defines an open-ended category of knowledge 
schemas. The Gary Hart schema is a member of that category, since it fits the generic-level schema given the correspondences stated above. It appears at present that such analogies use this metaphorical mechanism. But it is common for analogies to use other metaphorical mechanisms as well, for instance, the Great Chain Metaphor and the full range of conventional mappings in the conceptual system. Sentences like John is a wolf or Harry is a pig use the Great Chain metaphor (see Lakoff \& Turner, 1989, ch. 4). A good example of how the rest of the metaphor system interacts with GENERIC IS SPECIFIC is the well-known example of Glucksberg and Keysar (this volume), My job is a jail. First, the knowledge schema for a jail includes the knowledge that a jail imposes extreme physical constraints on a prisoner's movements. The GENERIC IS SPECIFIC metaphor preserves the image-schematic structure of the knowledge schema, factoring out the specific details of the prisoner and the jail: $\mathrm{X}$ imposes extreme physical constraints on Y's movements. But now two additional conventional metaphors apply to this generic-level schema: The Event Structure Metaphor, with the submetaphor ACTIONS ARE SELF-PROPELLED MOVEMENTS, and PSYCHOLOGICAL FORCE IS PHYSICAL FORCE. These metaphors map $X$ imposes extreme physical constraints on $Y$ 's movements into $X$ imposes extreme psychological constraints on Y's actions. The statement My job is a jail imposes an interpretation in which $\mathrm{X}=$ my job and $\mathrm{Y}=$ me, and hence yields the knowledge that My job imposes extreme psychological constraints on my actions. Thus, the mechanism for understanding $M y$ job is a jail uses very common, independently existing metaphors: GENERIC IS SPECIFIC, PSYCHOLOGICAL FORCE IS PHYSICAL FORCE, and The Event Structure Metaphor.

\section{The Glucksberg-Keysar Claim}

I mention this example because of the claim by Glucksberg and Keysar (this volume) that metaphor is simply a matter of categorization. However, in personal correspondence Glucksberg has written, We assume that people can judge and can also infer that certain basic level entities, such as 'jails' typify or are emblematic of a metaphoric attributive category such as "situations that are confining, unpleasant, etc." Glucksberg and Keysar give no theory of how it is possible to have such a metaphoric attributive category -- that is, how it possible for one kind of thing (a general situation) to be metaphorically categorized in terms of a fundamentally spatial notion like 'confining.' Since Glucksberg is not in the business of describing the nature of conceptual systems, he does not see it as his job to give such an account. I have argued in this paper that the general principle governing such cases is the Event Structure Metaphor. If such a metaphor exists in our conceptual system, then Glucksberg's 'jail' example is accounted for automatically and his categorization theory is not needed. Indeed, the category he needs -- situations that are confining, unpleasant, etc. -- is a metaphoric attributive category. That is, to get the appropriate categories in their categorization theory of metaphor he needs an account of metaphor. But given such an account of metaphor, their metaphor-as-categorization theory becomes unnecessary. Even worse for the Glucksberg-Keysar theory, it cannot account for either everyday conceptual metaphor of the sort we have been discussing or for really rich poetic metaphor, such as one finds in the works of, say, Dylan Thomas, or for image-metaphor of the sort common in the examples cited above from the Sanskrit, Navaho and surrealist traditions. Since it does not even attempt to deal with most of the data covered by the contemporary theory of metaphor, it cannot 
account for how metaphor works.

\section{More On Novel Metaphor}

At the time most of the papers in this volume were written (the late 1970's), metaphor was taken to mean novel metaphor, since the huge system of conventional metaphor had barely been noticed. For that reason, the authors never took up the question of how the system of conventional metaphor functions in the interpretation of novel metaphor. We have just seen one such example. Let us consider some others. As common as novel metaphor is, its occurrence is rare by comparison with conventional metaphor, which occurs in most of the sentences we utter. Our everyday metaphor system, which we use to understand concepts as commonplace as TIME, STATE, CHANGE, CAUSATION, PURPOSE, etc. is constantly active, and is used maximally in interpreting novel metaphorical uses of language. The problem with all the older research on novel metaphor is that it completely missed the major contribution played by the conventional system. As Turner and I discussed in detail (Lakoff \& Turner, 1989), there are three basic mechanisms for interpreting linguistic expressions as novel metaphors: Extensions of conventional metaphors; Generic-level metaphors; Image-metaphors. Most interesting poetic metaphor uses all of these superimposed on one another. Let us begin with examples of extensions of conventional metaphors. Dante begins the Divine Comedy: In the middle of life's road I found myself in a dark wood. Life's road evokes the domain of life and the domain of travel, and hence the conventional LIFE IS A JOURNEY metaphor that links them. I found myself in a dark wood evokes the knowledge that if it's dark you cannot see which way to go. This evokes the domain of seeing, and thus the conventional metaphor that KNOWING IS SEEING, as in expressions like I see what you're getting at, His claims aren't clear, The passage is opaque, etc. This entails that the speaker doesn't know which way to go. Since the LIFE IS A JOURNEY metaphor specifies destinations are life goals, it is entailed that the speaker does not know what life goals to pursue, that is, he is without direction in his life. All of this uses nothing but the system of conventional metaphor, ordinary knowledge structure evoked by the conventional meaning of the sentence, and metaphorical inferences based on that knowledge structure. Another equally simple case of the use of the conventional system is Robert Frost's

$\begin{array}{llllll}\text { Two roads } & \text { diverged } & \text { in } & \text { a } & \text { wood, } & \text { and } \\ \text { I took } & \text { the } & \text { I } & \text { less } & \text { traveled } & \text { by, }\end{array}$ And that has made all the difference.

Since Frost's language often does not overtly signal that the poem is to be taken metaphorically, incompetent English teachers occasionally teach Frost as if he were a nature poet, simply describing scenes. (I have actually had students whose high school teachers taught them that!) Thus, this passage could be read nonmetaphorically as being just about a trip on which one encounters a crossroads. There is nothing in the sentences themselves that forces one to a metaphorical interpretation. But, since it is about travel and encountering crossroads, it evokes a knowledge of journeys. This activates the system of conventional metaphor we have just discussed, in which longterm, purposeful activities are understood as journeys, and further, how life and careers can also be understood as one-person journeys (love relationships, involving two travelers, are ruled out here). The poem is typically taken as being about life and a choice of life goals, though it might also be interpreted as being about careers and careers paths, or about some 
longterm, purposeful activity. All that is needed to get the requisite range of interpretations is the structure of conventional metaphors discussed above, and the knowledge structure evoked by the poem. The conventional mapping will apply to the knowledge structure yielding the appropriate inferences. No special mechanisms are needed.

\section{Searle's Theory}

At this point I will leave off discussion of other more complex poetic examples, since they require lengthy discussion and since such discussion can be found in Lakoff and Turner (1989), Turner (1987), and Turner (1991). Instead, I will confine myself to discussing three examples from John Searle's Chapter (this volume). Consider first Disraeli's remark, I have climbed to the top of the greasy pole. Certainly, this could be taken nonmetaphorically, but its most likely metaphorical interpretation is via the CAREER IS A JOURNEY metaphor. This metaphor is evoked jointly by source domain knowledge about pole-climbing (which is effortful, self-propelled, destination-oriented motion upward) and knowledge that the metaphor involves effortful, self-propelled, destinationoriented motion upward. Part of the knowledge evoked is that the speaker is as high as he can get on that particular pole, that the pole was difficult to climb, that the climb probably involved backwards motion, that it is difficult for someone to stay at the top of a greasy pole, and that he will most likely slide down again. The CAREER IS A JOURNEY metaphor maps this knowledge onto corresponding knowledge about the speaker's career: the speaker has as much status as he or she can get in that particular career, that is was difficult to get to that point in the career, that it probably involved some temporary loss of status along the way, that it is difficult to maintain this position, and that he or she will probably lose status before long. All this follows with nothing more that the conventional career-asjourney mapping, which we all share as part of our metaphorical systems, plus knowledge about climbing greasy poles. The second example of Searle's I will consider is Sally is a block of ice. Here there is a conventional metaphor that AFFECTION IS WARMTH, as in ordinary sentences like She's a warm person, He was cool to me, etc. A block of ice evokes the domain of temperature, and, since it is predicated of a person, it also evokes knowledge of what a person can be. Jointly, both kinds of knowledge activate AFFECTION IS WARMTH. Since a block of ice is something that is very cold and not able to become warm quickly or easily, this knowledge is mapped onto Sally's being very unaffectionate and not being able to become affectionate quickly or easily. Again, common knowledge and a conventional metaphor that we all have is all that is needed. Finally, Searle discusses The hours crept by as we waited for the plane. Here we have a verb of motion predicated of a time expression; the former activates the knowledge about motion through space and the latter activates the time domain. Jointly, they activate the time-as-moving-object mapping. Again the meaning of the sentence follows only from everyday knowledge and the everyday system of metaphorical mappings. Searle accounts for such cases by his Principle 4, which says that we just do perceive a connection which is the basis of the interpretation. This is vague and doesn't say what the perceived connection is or why we just do perceive it. When we spell out the details of all such perceived connections, they turn out to be the system of conceptual metaphors that I have been describing. But given that system, Searle's theory and his principles become unnecessary. In addition, Searle's account of literal meaning makes most of the usual false assumptions that 
accompany that term. Searle assumes that all everyday, conventional language is literal and not metaphorical. He would thus rule out every example of conventional metaphor that is described not only in this paper, but in the whole literature of the field. The study of the metaphorical subsystem of our conceptual system is a central part of synchronic linguistics. The reason is that much of our semantic system, that is, our system of concepts, is metaphorical, as we saw above. It is because this huge system went unnoticed prior to 1980 that authors like Searle, Sadock, and Morgan could claim that metaphor was outside of synchronic linguistics and in the domain of principles of language use.

\section{The Experiential Basis Of Metaphor}

The conceptual system underlying a language contains thousands of conceptual metaphors -- conventional mappings from one domain to another, such as the Event Structure Metaphor. The novel metaphors of a language are, except for image metaphors, extensions of this large conventional system. Perhaps the deepest question that any theory of metaphor must answer is this: Why do we have the conventional metaphors that we have? Or alternatively: Is there any reason why conceptual systems contain one set of metaphorical mappings rather than another? There do appear to be answers to these questions for many of the mappings found so far, though they are in the realm of plausible accounts, rather than in the realm of scientific results. Take a simple case: the MORE IS UP metaphor, as seen in expressions like: Prices rose. His income went down. Unemployment is up. Exports are down. The number of homeless people is very high. There are other languages in which MORE IS UP and LESS IS DOWN, but none in which the reverse is true, where MORE IS DOWN and LESS IS UP. Why not? The answer given in the contemporary theory is that the MORE IS UP metaphor is grounded in experience-in the common experiences of pouring more fluid into a container and seeing the level go up, or adding more things to a pile and seeing the pile get higher. These are thoroughly pervasive experiences; we experience them every day of our lives. They are experiences with a structure-a correspondence between the conceptual domain of quantity and the conceptual domain of verticality: MORE corresponds in such experiences to UP and LESS corresponds to $D O W N$. These correspondences in real experience form the basis for the correspondence in the metaphorical cases, which go beyond the cases in real experience: in Prices rose there is no correspondence in real experience between quantity and verticality, but understanding quantity in terms of verticality makes sense because of the existence of a regular correspondence in so many other cases. Consider another case: What is the basis of the widespread KNOWING IS SEEING metaphor, as in expressions like: I see what your saying. His answer was clear. This paragraph is murky. He was so blinded by ambition that he never noticed his limitations. The experiential basis, in this case, is the fact that most of what we know comes through vision, and that in the overwhelming majority of cases, if we see something, then we know it is true. Consider still another case: Why, in the Event Structure Metaphor, is achieving a purpose understood as reaching a destination (in the location subsystem) and as acquiring a desired object (in the object subsystem)? The answer again seems to be correspondences in everyday experience. To achieve most of our everyday purposes, we either have to move to some destination or acquire some object. If you want a drink of water, you've got to go to the water fountain. If you want to be in the sunshine, you have to move to where the sunshine is. And if you want to 
write down a note, you got to get a pen or pencil. The correspondences between achieving purposes and either reaching destinations or acquiring objects is so utterly common in our everyday existence, that the resulting metaphor is completely natural. But what about the experiential basis of A PURPOSEFUL LIFE IS A JOURNEY? Recall that that mapping is in an inheritance hierarchy, where life goals are special cases of purposes, which are destinations in the event structure metaphor. Thus, A PURPOSEFUL LIFE IS A JOURNEY inherits the experiential basis of PURPOSES ARE DESTINATIONS. Thus, inheritance hierarchies provide indirect experiential bases, in that a metaphorical mapping lower in a hierarchy can inherit its experiential basis indirectly from a mapping higher in the hierarchy. Experiential bases motivate metaphors, they do not predict them. Thus, not every language has a MORE IS UP metaphor, though all human beings experience a correspondence between MORE and UP in their experience. What this experiential basis does predict is that no language will have the opposite metaphor LESS IS UP. It also predicts that a speaker of language that does not have that metaphor will be able to learn that metaphor much more easily than the opposite metaphor.

\section{Realizations of Metaphor}

Consider objects like thermometers and stock market graphs, where increases in temperature and prices are represented as being up and decreases as being down. These are real man-made objects created to accord with the MORE IS UP metaphor. They are objects in which there is a correlation between MORE and UP. Such objects are a lot easier to read and understand than if they contradicted the metaphor, say, if increases were represented as down and decreases as up. Such objects are ways in which metaphors impose a structure on real life, through the creation of new correspondences in experience. And of course, once such real objects are created in one generation, those objects serve as an experiential basis for that metaphor in the next generation. There are a great many ways in which conventional metaphors can be made real. Metaphors can be realized in obvious imaginative products such as cartoons, literary works, dreams, visions, and myths. But metaphors can be made real in less obvious ways as well, in physical symptoms, social institutions, social practices, laws, and even foreign policy and forms of discourse and of history. Let us consider some examples:

Cartoons:

Conventional metaphors are made real in cartoons. A common example is the realization of the ANGER IS A HOT FLUID IN A CONTAINER metaphor, in which one can be boiling mad or letting off steam. In cartoons, anger is commonly depicted by having steam coming out the character's ears. Similarly, social clumsiness is indicated by having a cartoon character fall on his face.

Literary works:

It is common for the plot of novel to be a realization of the PURPOSEFUL LIFE IS A JOURNEY metaphor, where the course of a life takes the form of an actual journey. Pilgrim's Progress is a classical example.

Rituals: 
Consider the cultural ritual in which a newborn baby is carried upstairs to insure his or her success. The metaphor realized in this ritual is STATUS IS $U P$, exemplified by sentences such as: He clawed his way to the top. He climbed the ladder of success. You'll rise in the world.

Dream Interpretation:

Conceptual metaphors consitute the vocabulary of dream interpretation. It is the collection of our everyday conceptual metaphors that make dream interpretations possible. Consider one of the most celebrated of all dream interpretations: Joseph's interpretation of Pharoah's dream from Genesis. In Pharoah's dream, he is standing on the river bank, when seven fat cows come out of the river, followed by seven lean cows that eat the seven fat ones and still remain lean. Then Pharoah dreams again. This time he sees seven full and good ears of corn growing, and then seven withered ears growing after them. The withered ears devour the good ears. Joseph interprets the two dreams as a single dream. The seven fat cows and full ears are good years and the seven lean cows and withered ears are famine years that follow the good years. The famine years devour what the good years produce. This interpretation makes sense to us because of a collection of conceptual metaphors in our conceptual system -- metaphors that have been with us since Biblical times.

- The first metaphor used is: TIMES ARE MOVING ENTITIES. A river is a common metaphor for the flow of time; the cows are individual entities (years) emerging from the flow of time and moving past the observer; the ears of corn are also entities that come into the scene.

- The second metaphor used is ACHIEVING A PURPOSE IS EATING, where being fat indicates success being lean indicates failure. This metaphor is combined with the most common of metonymies: A PART STANDS FOR THE WHOLE. Since cows and corn were typical of meat and grain eaten, each single cow stands for all the cows raised in a year and each ear of corn for all the corn grown in a year.

- The final metaphor used is: RESOURCES ARE FOOD, where using up resources is eating food. The devouring of the good years by the famine years is interpreted as indicating that all the surplus resources of the good years will be used up by the famine years.

The interpretation of the whole dream is thus a composition of three conventional metaphors and one metonymy. The metaphoric and metonymic sources are combined to form the reality of the dream.

Myths:

In the Event Structure metaphor, there is a submapping EXTERNAL EVENTS ARE LARGE, MOVING OBJECTS that can exerted a force upon you and thereby effect whether you achieve your goals. In English the special cases of such objects are things, fluids, and horses. Pamela Morgan (in unpublished work) has observed that in Greek Mythology, Poseidon is the god of the sea, 
earthquakes, horses and bulls. The list might seem arbitrary, but Morgan observes that these are all large moving objects that can exert a force on you. Morgan surmises that this is not an obvious list. The sea, earthquakes, horses, and bulls are all large moving objects that can exert a significant force. Poseidon, she surmises, should really be seen as the god of external events.

Physical symptoms:

The unconscious mind makes use our unconscious system of conventional metaphor, sometimes to express psychological states in terms of physical symptoms. For example, in the Event Structure metaphor, there is a submapping DIFFICULTIES ARE IMPEDIMENTS TO MOTION which has, as a special case, DIFFICULTIES ARE BURDENS. It is fairly common for someone encountering difficulties to walk with his shoulders stooped, as if carrying a heavy weight that is burdening him.

Social institutions:

We have a TIME IS MONEY metaphor, shown by expressions like:

He's wasting time.

I have to budget my time.

This will save you time.

I've invested a lot of time in that.

He doesn't use his time profitably.

This metaphor came into English about the time of the industrial revolution, when people started to be paid for work by the amount of time they worked. Thus, the factory led to the institutional pairing of periods of time with amounts of money, which formed the experiential basis of this metaphor. Since then, the metaphor has been realized in many other ways. The budgeting of time has spread throughout American culture.

Social practices:

There is conceptual metaphor that SEEING IS TOUCHING, where the eyes are limbs and vision is achieved when the object seen is touched.

Examples are:

My eyes picked out every detail of the pattern.

He ran his eyes over the walls.

He couldn't take his eyes off of her.

Their eyes met.

His eyes are glued to the $t v$.

The metaphor is made real in the social practice of avoiding eye contact on the street, and in the social prohibition against undressing someone with your eyes. 
Laws:

Law is major area where metaphor is made real. For example, CORPORATIONS ARE PERSONS is a tenet of American law, which not only enables corporations to be harmed and assigned responsibility so that they can be sued when liable, but also gives corporations certain First Amendment rights.

Foreign policy:

A STATE IS A PERSON is one of the major metaphors underlying foreign policy concepts. Thus, there are friendly states, hostile states, etc. Health for a state is economic health and strength is military strength. Thus a threat to economic health can be seen as a death threat, as when Iraq was seen to have a stanglehold on the economic lifeline of the U.S. Strong states are seen as male, and weak states as female, so that an attack by a strong state on a weak state can be seen as a rape, as in the rape of Kuwait by Iraq. A just war is conceptualized as a fairy tale with villain, victim, and hero, where the villain attacks the victim and the hero rescues the victim. Thus, the U.S. in the Gulf War was portrayed as having rescued Kuwait. As President Bush said in his address to Congress, The issues couldn't have been clearer: Iraq was the villain and Kuwait, the victim.

Forms of discourse:

Common metaphors are often made real in discourse forms. Consider four common academic discourse forms: the Guided Tour, the Heroic Battle, and the Heroic Quest.

The Guided Tour is based on the metaphor that THOUGHT IS MOTION, where ideas are locations and one reasons step-by-step, reaches conclusions, or you fail to reach a conclusion if you are engaged in circular reasoning. Communication in this metaphor is giving someone a guided tour of some rational argument or of some intellectual terrain. The present paper is an example of such a guided tour, where I, the author, am the tour guide who is assumed to be thoroughly familiar with the terrain, and where the terrain surveyed is taken as objectively real.

The discourse form of the Heroic Battle is based on the metaphor that $A R G U M E N T$ IS WAR. The author's theory is the hero, the opposing theory is the villain, and words are weapons. The battle is in the form of an argument defending the hero's position and demolishing the villain's position.

The Heroic Quest discourse form is based on the metaphor that knowledge is a valuable but elusive object that can be discovered if one perseveres. The scientist is the hero on a quest for knowledge, and the discourse form is an account of his difficult journey of discovery. What is discovered is, of course, a real entity. What makes all of these cases realizations of metaphors is that in each case there is something real structured by conventional metaphor, and which is made comprehensible, or even natural, by those everyday metaphors. What is real differs in each case: an object like a thermometer or graph, an experience like a dream, an action like a ritual, a form of discourse, etc.

What these examples reveal is that a lot of what is real in a society or in the 
experience of an individual is structured and made sense of via conventional metaphor. Experiential bases and realizations of metaphors are two sides of the same coin: they are both correlations in real experience that have the same structure as the correlations in metaphors. The difference is that experiential bases precede, ground, and make sense of conventional metaphorical mappings, while realizations follow, and are made sense of, via the conventional metaphors. And as we noted above, one generation's realizations of a metaphor can become part of the next generation's experiential basis for that metaphor.

\section{Summary of Results}

As we have seen, the contemporary theory of metaphor is revolutionary in many respects. To give you some idea how revolutionary, here is a list of the basic results that differ from most previous accounts.

\section{The Nature of Metaphor}

- Metaphor is the main mechanism through which we comprehend abstract concepts and perform abstract reasoning.

- Much subject matter, from the most mundane to the most abstruse scientific theories, can only be comprehended via metaphor.

- Metaphor is fundamentally conceptual, not linguistic, in nature.

- Metaphorical language is a surface manifestation of conceptual metaphor.

- Though much of our conceptual system is metaphorical, a significant part of it is nonmetaphorical. Metaphorical understanding is grounded in nonmetaphorical understanding.

- Metaphor allows us to understand a relatively abstract or inherently unstructured subject matter in terms of a more concrete, or at least a more highly structured subject matter.

\section{The Structure of Metaphor}

- Metaphors are mappings across conceptual domains.

- Such mappings are asymmetric and partial.

- Each mapping is a fixed set of ontological correspondences between entities in a source domain and entities in a target domain.

- When those fixed correspondences are activated, mappings can project source domain inference patterns onto target domain inference patterns.

- Metaphorical mappings obey the Invariance Principle: The image-schema structure of the source domain is projected onto the target domain in a way that is consistent with inherent target domain structure.

- Mappings are not arbitrary, but grounded in the body and in everyday experience and knowledge.

- A conceptual system contains thousands of conventional metaphorical mappings, which form a highly structured subsystem of the conceptual system. 
- There are two types of mappings: conceptual mappings and imagemappings; both obey the Invariance Principle.

\section{Some Aspects of Metaphor}

- The system of conventional conceptual metaphor is mostly unconscious, automatic, and is used with no noticeable effort, just like our linguistic system and the rest of our conceptual system.

- Our system of conventional metaphor is alive in the same sense that our system of grammatical and phonological rules is alive; namely, it is constantly in use, automatically and below the level of consciousness.

- Our metaphor system is central to our understanding of experience and to the way we act on that understanding.

- Conventional mappings are static correspondences, and are not, in themselves, algorithmic in nature. However, this by no means rules out the possibility that such static correspondences might be used in language processing that involves sequential steps.

- Metaphor is mostly based on correspondences in our experiences, rather than on similarity.

- The metaphor system plays a major role in both the grammar and lexicon of a language.

- Metaphorical mappings vary in universality; some seem to be universal, others are widespread, and some seem to be culture- specific.

- Poetic metaphor is, for the most part, an extension of our everyday, conventional system of metaphorical thought.

These are the conclusions that best fit the empirical studies of metaphor conducted over the past decade or so. Though much of it is inconsistent with traditional views, it is by no means all new, and some ideas-e.g., that abstract concepts are comprehended in terms of concrete concepts-have a long history.

\section{Concluding Remarks}

The evidence supporting the contemporary theory of metaphor is voluminous and grows larger each year as more research in the field is done. The evidence, as we saw above, comes from five domains:

- Generalizations over polysemy

- Generalization over inference patterns

- Generalizations over extensions to poetic cases

- Generalizations over semantic change

- Psycholinguistic experiments

I have discussed only a handful of examples of the first three of these, hopefully enough to make the reader curious about the field. But evidence is convincing only if it can count as evidence. When does evidence fail to be evidence? Unfortunately, all too often. It is commonly the case that certain fields of inquiry are defined by assumptions that rule out the possibility of counterevidence. When 
a defining assumption of a field comes up against evidence, the evidence usually loses: the practitioners of the field must ignore the evidence if they want to keep the assumptions that define the field they are committed to. Part of what makes the contemporary theory of metaphor so interesting is that the evidence for it contradicts the defining assumptions of so many academic disciplines. In my opinion, this should make one doubt the defining assumptions of all those disciplines. The reason is this: The defining assumptions of the contemporary theory of metaphor are minimal. There are only two. The Generalization Commitment: To seek generalizations in all areas of language, including polysemy, patterns of inference, novel metaphor, and semantic change. The Cognitive Commitment: To take experimental evidence seriously. But these are nothing more than commitments to the scientific study of language and the mind. No initial commitment is made as to the form of an answer to the question of what is metaphor. However, the defining assumptions of other fields do often entail a commitment about the form of an answer to that question. It is useful, in an interdisciplinary volume of this sort, to spell out exactly what those defining assumptions are, since they will often explain why different authors reach such different conclusions about the nature of metaphor.

\section{Literal Meaning Commitments}

I started this Chapter with a list of the false assumptions about literal meaning that are commonly made. These assumptions are, of course, false only relative to the kinds of evidence that supports the contemporary theory of metaphor. If one ignores all such evidence, then the assumptions can be maintained without contradiction. Assumptions about literality are the locus of many of the contradictions between the contemporary theory of metaphor and various academic disciplines. Let us review those assumptions. In the discussion of literal meaning given above, I observed that it is taken as definitional that: What is literal is not metaphorical. The false assumptions and conclusions that usually accompany the word literal are:

- All everyday conventional language is literal, and none is metaphorical.

- All subject matter can be comprehended literally, without metaphor.

- Only literal language can be contingently true or false.

- All definitions given in the lexicon of a language are literal, not metaphorical.

- The concepts used in the grammar of a language are all literal; none are metaphorical.

We will begin with the philosophy of language. The Generalization Commitment and the Cognitive Commitment are not definitional to the philosophy of language. Indeed, most philosophers of language would feel no need to abide by them, for a very good reason. The philosophy of language is typically not seen as an empirical discipline, constrained by empirical results, such as those that arise by the application of the Generalization and Cognitive Commitments. Instead, the philosophy of language is usually seen as an a priori discipline, one which can be pursued using the tools of philosophical analysis alone, rather than the tools of empirical research. Therefore, all the evidence that has been brought forth for the contemporary theory of metaphor simply will not matter for most philosophers of language. In addition, the philosophy of language comes with its own set of 
defining assumptions, which entail many of the false assumptions usually associated with the word literal. Most practitioners of the philosophy of language usually make one or more of the following assumptions.

- The correspondence theory of truth.

- Meaning is defined in terms of reference and truth.

- Natural language semantics is to be characterized by the mechanisms of mathematical logic, including model theory.

These assumptions entail the traditional false assumptions associated with the word literal. Thus the very field of philosophy of language comes with defining assumptions that contradict the main conclusions of the contemporary theory of metaphor. Consequently, we can see why most philosophers of language have the range of views on metaphor that they have: They accept the traditional literalfigurative distinction. They may, like Davidson (1981), say that there is no metaphorical meaning, and that most metaphorical utterances are either trivially true or trivially false. Or, like Grice (1989, p. 34) and Searle (this volume), they will assume that metaphor is in the realm of pragmatics, that is, that a metaphorical meaning is no more than the literal meaning of some other sentence which can be arrived at by some pragmatic principle. This is required, since the only real meaning for them is literal meaning, and pragmatic principles are those principles that allow one to say one thing (with a literal meaning) and mean something else (with a different, but nonetheless literal, meaning). Much of generative linguistics accepts one or more of these assumptions from the philosophy of language. The field of formal semantics accepts them all, and thus formal semantics, by its defining assumptions, is at odds with the contemporary theory of metaphor. Formal semantics simply does not see it as its job $>$ to account for the generalizations discussed in this paper. From the perspective of formal semantics, the phenomena that the contemporary theory of metaphor is concerned with are either nonexistent or uninteresting, since they lie outside the purview of the discipline. That is why Jerrold Sadock in his chapter in this volume claims that metaphor lies outside of synchronic linguistics. Since he accepts mathematical logic as the correct approach to natural language semantics, Sadock must see metaphor as being outside of semantics proper. He must, therefore, also reject the entire enterprise of the contemporary theory of metaphor. And Morgan (this volume), also accepting those defining assumptions of the philosophy of language, agrees with Grice and Searle that metaphor is a matter of pragmatics.

Chomsky's theory of government and binding also accepts crucial assumptions from the philosophy of language that are inconsistent with the contemporary theory of metaphor. Government and binding, following my early theory of generative semantics, assumes that semantics is to be represented in terms of logical form. Government and binding, like generative semantics, thus rules out the very possibility that metaphor might be part of natural language semantics as it enters into grammar. Because of this defining assumption, I would not expect government and binding theorists to become concerned with the phenomena covered by the contemporary theory of metaphor.

Interestingly, much of continental philosophy and deconstructionism is also characterized by defining assumptions that are at odds with the contemporary theory of metaphor. Nietzsche (see, Johnson, 1981) held that all language is metaphorical, which is at odds with those results that indicate that a significant 
amount of everyday language is not metaphorical. Much of continental philosophy, observing that conceptual systems change through time, assumes that conceptual systems are purely historically contingent-that there are no conceptual universals. Though conceptual systems do change through time, there do, however, appear to be universal, or at least very widespread, conceptual metaphors. The event structure metaphor is my present candidate for a metaphorical universal. Continental philosophy also comes with a distinction between the study of the physical world, which can be scientific, and the study of human beings, which it says cannot be scientific. This is very much at odds with the conceptual theory of metaphor, which is very much a scientific enterprise.

Finally, the contemporary theory of metaphor is at odds with certain traditions in symbolic artificial intelligence and information processing psychology. Those fields assume that thought is a matter of algorithmic symbol manipulation, of the sort done by a traditional computer program. This defining assumption puts it at odds with the contemporary theory of metaphor in two respects: First, the contemporary theory has an image-schematic basis: The invariance hypothesis applies both to image-metaphors and characterizes constraints on novel metaphor. Since symbol-manipulation systems cannot handle image-schemas, they cannot deal with image-metaphors or imagable idioms. Second, those traditions must characterize metaphorical mapping as an algorithmic process, which typically takes literal meanings as input and gives a metaphorical reading as output. This is at odds with cases where there are multiple, overlapping metaphors in a single sentence, and which require the simultaneous activation of a number of metaphorical mappings.

The contemporary theory of metaphor is thus not only interesting for its own sake. It is especially interesting for the challenge it brings to other disciplines. For, if the results of the contemporary theory are accepted, then the defining assumptions of whole disciplines are brought into question.

\section{Notes}

This research was supported in part by grants from the Sloan Foundation and the National Science Foundation (IRI-8703202) to the University of California at Berkeley. The following colleagues and students helped with this paper in a variety of ways, from useful comments to allowing me to cite their research: Ken Baldwin, Claudia Brugman, Jane Espenson, Sharon Fischler, Ray Gibbs, Adele Goldberg, Mark Johnson, Karin Myhre, Eve Sweetser, and Mark Turner.

\section{Appendix: An Annotated Bibliography}

Most of the papers in this edition also appeared in the first edition of 1979 and thus predate the contemporary theory of metaphor. Because of this, I thought might be a service to readers to provide a short annotated bibliography of fundamental books and papers on the contemporary theory written since the first edition of this volume appeared.

Gibbs, Raymond W., Jr. 1990. Psycholinguistic studies on the conceptual basis of idiomaticity. Cognitive Linguistics, 1-4: 417-462.

A survey of psycholinguistic results demonstrating the cognitive reality of conceptual metaphor and imagable idioms. 
Johnson, Mark. 1981. Philosphical Perspectives on Metaphor Minneapolis: University of Minnesota Press.

The best collection of papers by philosophers on metaphor. Thae author's introduction is the best short historical survey of the history of metaphor in philsophy.

Johnson, Mark. 1987. The Body in the Mind: the Bodily Basis of Meaning, Reason and Imagination. Chicago: University of Chicago Press.

A discussion of philosophical issues arising from the discovery of the system of conceptual metaphor.

Kovecses, Zoltan. 1990. Emotion Concepts. Springer-Verlag.

A thorough and voluminously documented demonstration that emotion is conceptualized metaphorically.

Lakoff, George. 1987. Women, Fire, and Dangerous Things: What Categories Reveal about the Mind. Chicago: University of Chicago Press.

A survey of contemporary literature on categorization, including the role of metaphor in forming categories categories. Includes a general theory of meaning assimilating conceptual metaphor and other aspects of cognitive semantics.

Lakoff, George. 1989. Philosophical Speculation and Cognitive Science. In Philosophical Psychology: 2,1.

A discussion of the differing assumptions behind generative semantics and generative grammar.

Lakoff, George. 1991. Metaphor and War: The Metaphor System Used To Justify War in the Gulf.

Distributed via electronic bulletin boards, January, 1991. Reprinted in Brien Hallet (ed.), Engulfed in War: Just War and the Persian Gulf, Honolulu: Matsunaga Institute for Peace, 1991. Also in: Journal of Urban and Cultural Studies, vol. 2, no. 1, 1991. Also in: Vietnam Generation Newsletter, vol. 3, no. 2, No vember 1991. Also in: The East Bay Express, February, 1991. An analysis of the metaphorical system used in the public discourse and expert policy deliberations on the Gulf War, together with what the metaphors hid, and a critique of the war based on this analysis.

Lakoff, George and Claudia Brugman. 1986. Argument Forms in Lexical Semantics. In Nikiforidou et al. (eds.) Proceedings of the Twelfth Annual Meeting of the Berkeley Linguistics Society: 442-454.

A survey of the argument forms used in justifying metaphorical analysis and a comparison with corresponding argument forms in syntax and phonology.

Lakoff, George and Johnson, Mark. 1980. Metaphors We Live By. Chicago: University of Chicago Press.

The first book outlining the con temporary theory of metaphor. 
Lakoff, George and Turner, Mark. 1989. More Than Cool Reason: A Field Guide to Poetic Metaphor Chicago: University of Chicago Press.

A survey of the mechanisms of poetic metaphor, replete with examples.

Sweetser, Eve. 1990. From Etymology to Pragmatics: The Mind-as-Body Metaphor in Semantic Structure and Semantic Change. Cambridge: Cambridge Univer sity Press.

The best work to date on the role of metaphor in semantic change, and the metaphorical basis of pragmatics.

Talmy, Leonard. 1985. Force Dynamics in Language and Thought. In Papers from the Parasession on Causatives and Agentivity. Chicago: Chicago Linguistic Society.

The analysis that led to the study of the metaphorical basis of modality and causation.

Turner, Mark. 1987. Death is the Mother of Beauty: Mind, Metaphor, Criticism. Chicago: University of Chicago Press.

A study of the regularities behind all the kinship metaphors from Chaucer to Wallace Stevens, including the role of metaphor in allegory. Turner also noticed the prevalence of the CAUSATION IS PROGENERATION metaphor and the constraint that was the precursor to the Invariance Principle.

Turner, Mark 1991. Reading Minds: The Study of English in the Age of Cognitive Science. Princeton: Princeton University Press.

A reevaluation of the profession of English and the study of the English language in the light of recent results on the nature of metaphor and other results in the cognitive sciences.

Winter, Steven L. 1989. Transcendental Nonsense, Metaphoric Reasoning, and the Cognitive Stakes for Law, 137 University of Pennsylvania Law Review.

The most comprehensive of Winter's many articles discussing the role of metaphor in law.

\section{References}

- Auster, Paul, ed. 1984. The Random House Book of Twentieth Century French Poetry. New York: Random House.

- Gibbs, Raymond W., Jr. 1990. Psycholinguistics studies on the conceptual basis of idiomaticity. Cognitive Linguistics, 1-4: 417-462.

- Grice, Paul 1989. Studies in the Way of Words Cambridge, Mass.: Harvard University Press. Johnson, Mark. 1981. Philosphical Perspectives on Metaphor Minneapolis: University of Minnesota Press.

- Johnson, Mark. 1987. The Body in the Mind: the Bodily Basis of Meaning, Reason and Imagination. Chicago: University of Chicago Press.

- Kovecses, Zoltan. 1990. Emotion Concepts. Springer- Verlag. 
- Lakoff, George. 1987. Women, Fire, and Dangerous Things: What Categories Reveal about the Mind. Chicago: University of Chicago Press.

- Lakoff, George. 1989. Philosophical Speculation and Cognitive Science. In Philosophical Psychology: 2,1.

- Lakoff, George and Claudia Brugman. 1986. Argument Forms in Lexical Semantics. In Nikiforidou et al. (eds.) Proceedings of the Twelfth Annual Meeting of the Berkeley Linguistics Society: 442-454.

- Lakoff, George and Johnson, Mark. 1980. Metaphors We Live By. Chicago: University of Chicago Press.

- Lakoff, George and Turner, Mark. 1989. More Than Cool Reason: A Field Guide to Poetic Metaphor Chicago: University of Chicago Press. Merwin, W. S. 1973. Asian Figures. New York: Atheneum.

- Merwin, W. S., and Masson, J. Moussaieff, trs. 1981. The Peacock's Egg. San Francisco: North Point Press.

- Rothenberg, Jerome, ed. 1985. Technicians of the Sacred. Berkeley and Los Angeles: University of California Press.

- Sweetser, Eve. 1990. From Etymology to Pragmatics: The Mind-as-Body Metaphor in Semantic Structure and Semantic Change. Cambridge: Cambridge University Press.

- Talmy, Leonard. 1985. Force Dynamics in Language and Thought. In Papers from the Parasession on Causatives and Agentivity. Chicago: Chicago Linguistic Society.

- Turner, Mark. 1987. Death is the Mother of Beauty: Mind, Metaphor, Criticism. Chicago: University of Chicago Press.

- Turner, Mark 1991. Reading Minds: The Study of English in the Age of Cognitive Science. Princeton: Princeton University Press. 